\title{
Producir azúcar en la Patagonia. El ingenio San Lorenzo, un malogrado proyecto de industrialización de remolacha azucarera (Río Negro, 1927-1941)
}

\section{Daniel Moyano}

Consejo Nacional de Investigaciones Científicas y Técnica, Instituto Superior de Estudios Sociales, Universidad Nacional de Tucumán, Argentina moyano79@gmail.com

Cita sugerida: Moyano, D. y Bandieri, S. (2018). Producir azúcar en la Patagonia. El ingenio San Lorenzo, un malogrado proyecto de industrialización de remolacha azucarera (Río Negro, 1927-1941). Mundo Agrario, 19(42), e094. https://doi.org/10.24215/15155994e094

Recibido: 07 mayo 2018 - Aceptado: 22 septiembre 2018 - Publicado: 07 diciembre 2018 


\section{Producir azúcar en la Patagonia. El ingenio San Lorenzo, un malogrado proyecto de industrialización de remolacha azucarera (Río Negro, 1927-1941)}

Produce sugar in Patagonia. The San Lorenzo sugar mill, a failed sugar beet industrialization project (Río Negro, 1927-1941)

Daniel Moyano

Consejo Nacional de Investigaciones Cientificas y Técnicas, Instituto Superior de

Estudios Sociales, Universidad Nacional de Tucumán, Argentina

moyano79@gmail.com

Susana Bandieri

Consejo Nacional de Investigaciones Cientificas y Técnicas, Instituto Patagónico de

Humanidades y Ciencias Sociales, Universidad Nacional del Comahue, Argentina

susana.bandieri@gmail.com

\section{Resumen:}

En Argentina, la demanda interna de azúcar fue provista por la industria azucarera con base en la caña, desarrollada principalmente en la región norte el país. Pero también se llevaron a cabo emprendimientos fabriles alternativos a partir del procesamiento de la remolacha. El más perdurable se implementó en el entonces Territorio Nacional de Río Negro. Nuestro objetivo es analizar el origen y desempeño productivo del ingenio San Lorenzo, así como los motivos de su prematuro fracaso. Se utilizará información de diferente índole como estadísticas nacionales y regionales, balances de la empresa, medios de prensa e informes técnicos de época. Palabras CLAVE: Empresarios, Región, Industria azucarera, Patagonia.

\section{Abstract:}

In Argentina, domestic sugar demand was provided by the sugar cane industry, developed mainly in the north region. But alternative manufacturing ventures were also carried out from the processing of sugar beet. The most enduring was implemented in the then National Territory of Río Negro. The aim is to analyze the origin and productive performance of the San Lorenzo sugar mill, as well as the reasons for its premature failure. Different types of information will be used, such as national and regional statistics, company balance sheets, press releases and technical reports from that period.

KEYWORDS: Entrepreneurs, Region, Sugar industry, Patagonia.

\section{INTRODUCCIÓN}

Al hablar de la industria azucarera en la Argentina resulta inevitable vincularla con las provincias septentrionales, especialmente con Tucumán, Salta y Jujuy. Esta asociación no carece de fundamentos, ya que entre finales del siglo XIX y comienzos del siglo XX se desarrolló en el actual cuadrante noroeste del país una de las agroindustrias más importantes en términos de capital invertido, tecnología incorporada y mano de obra empleada, que convirtió al complejo tucumano y luego a los restantes en los principales polos azucareros orientados a satisfacer la demanda interna. Dicha actividad se basó en el procesamiento de la caña de azúcar (saccharum officinarum), una gramínea de clima tropical por antonomasia que fue adaptada gradualmente a las zonas cálidas de las llanuras subtropicales, aunque es preciso señalar, a costa de una notoria merma en sus rendimientos. Pero la caña no fue el único cultivo sacarífero que se industrializó. La producción con base en la remolacha azucarera (beta vulgaris var. saccharifera), ampliamente difundida en Europa y luego 
en los Estados Unidos, compartió el mercado mundial del dulce y lideró los adelantos tecnológicos en esta agroindustria hasta el cambio de siglo, los que se adaptaron luego en los principales centros cañicultores y posteriormente se difundieron en las regiones de clima templado. ${ }^{1}$

En la Argentina, desde mediados del siglo XIX se advirtieron las aptitudes de diferentes zonas de la región central del país para el desarrollo extensivo de esta quenopodiácea y, a pesar de no haber logrado la suficiente atención, se reflotaron recurrentemente algunas iniciativas localizadas (Alazraqui Alonso, 1964). En los años de entresiglos se concretaron ensayos en campos experimentales de empresarios agrícolas y de medianos propietarios abiertos a incorporar cultivos con mayor rentabilidad, de estaciones experimentales públicas y de otras privadas pertenecientes a empresas ferroviarias. ${ }^{2}$ Los resultados halagüeños en diversos puntos de la campaña bonaerense promovieron la sanción de la ley nacional 2.907, del año 1892, para el fomento del cultivo de remolacha, pero sin aplicaciones concretas. Posteriormente, esta iniciativa tuvo varios correlatos a nivel provincial, como en el caso de Mendoza -ley 526 del año 1910- o de Córdoba -ley 3.188 de 1922- (Ferrarazzo, 1938, p. 37; Schleh, 1939, pp. 61-62,101-102). A la par, instituciones científicas como la Estación Experimental Agrícola de Tucumán --dependiente del gobierno de la provinciaensayó entre 1917 y 1926 con remolachas de distinta procedencia para aclimatarlas a un ambiente cálido subtropical, comprobando la posibilidad de complementarlas con la caña y, de ese modo, compensar los bajos rendimientos diferenciales de la gramínea (Estación Experimental Agrícola de Tucumán, 1917-1926). Pero la réplica más importante para la temática que tratamos correspondió a la provincia de Buenos Aires que, en 1910, mediante la ley 3.264, otorgó al Ing. Agr. Pedro Riccheri privilegios para instalar fábricas de remolacha en las zonas que juzgara aptas para el cultivo, especialmente en las jurisdicciones del sur. Dicha concesión fue prorrogada en varias oportunidades pero, al igual que las anteriores, no arribó a buen puerto (Schleh, pp. 95-98). Más adelante volveremos sobre esta disposición en particular.

Recién a finales de la década de 1920 se concretaron dos emprendimientos. El primero lo llevó a cabo la S.A. Cía. Azucarera de Cuyo, que construyó su fábrica en Media Agua, al sur de la provincia de San Juan. Dicho proyecto contó desde el principio con un decidido apoyo del gobierno provincial, particularmente de las administraciones de Federico y Aldo Cantoni, a través de medidas de estímulo como exenciones impositivas, cesión de tierras y derechos de riego. El otro emprendimiento, la S.A. Compañía Industrial y Agrícola San Lorenzo Ltda., fue el resultado de la iniciativa privada y emplazó su ingenio en el entonces Territorio Nacional de Río Negro, en San Lorenzo, a $15 \mathrm{~km}$ de la localidad de General Conesa (Véase Apéndice, Figura 1 y 2). ${ }^{3}$ Dichas fábricas encendieron sus calderas en mayo de 1929, dando inicio a las primeras zafras de remolacha azucarera en la Argentina.

Ambos proyectos se respaldaron en estudios auspiciosos de estaciones experimentales públicas y privadas (Alto de Sierra, en San Juan y Cinco Saltos, en el Alto Valle del río Negro), instituciones que señalaron la potencialidad del cultivo remolachero, tanto en rendimientos culturales como en contenido sacarino de las raíces. Estos resultados insuflaron esperanzas sobre un futuro industrial a partir del procesamiento de este tubérculo y representaron las principales bases para la organización de los emprendimientos azucareros. El acondicionamiento de superficies para el cultivo, la construcción de edificios y reparticiones necesarias para la producción y las maquinarias traídas del exterior, conllevaron una considerable inversión de capitales, transformando en pocos años a zonas sin una "tradición" manufacturera-industrial en polos productivos con perspectivas de desarrollo y poblamiento. Pero pronto el entusiasmo se truncó. El proyecto sanjuanino, con solo tres zafras discontinuas, cerró sus puertas y terminó en convocatoria de acreedores en 1933. El ingenio San Lorenzo, por su parte, trabajó con altibajos entre los años 1929 y 1941, para luego clausurar definitivamente el emprendimiento y liquidar la firma.

La pronta frustración de estas expectativas de desarrollo regional generó interpretaciones sesgadas, cultivadas por la prensa local y por sectores políticos de la época, que posteriormente fueron tomadas por los escritos históricos. En el caso específico del ingenio San Lorenzo, se fundó un imaginario social todavía persistente en la norpatagonia sobre la "asfixia" del emprendimiento remolachero por parte de intereses 
rivales del norte del país - ubicados en la histórica región del azúcar en Argentina (Campi, Teruel y Moyano, 2017)-. Si bien esta versión ha llevado a sostener algunos hechos sin duda incomprobables -como la propagación intencional de plagas o el sabotaje de la fábrica - no es menos cierto que los ingenios de escalas productivas reducidas erigidos fuera de la región núcleo tuvieron que sobrellevar condiciones desventajosas, particularmente evidentes en los debates que tuvieron lugar en el Congreso Nacional entre 1938 y 1939 , durante la discusión de un proyecto de ley que pretendía regular en todo el país la fluctuante producción azucarera. Dicha propuesta fue impulsada por el entonces Ministro de Agricultura Ing. José Padilla (ex administrador del ingenio tucumano San Pablo, de la familia Nougués), que exigía de manera insistente evitar el surgimiento de nuevas fábricas azucareras para poder limitar la producción nacional y así ordenar el mercado interno. ${ }^{4}$

El mencionado proyecto de ley, que no llegó a aprobarse, fue intensamente debatido a favor y en contra por sectores políticos, industriales, cañeros, obreros y por la prensa de tirada nacional y regional, dando lugar a las más diversas interpretaciones, desde aquellos que sostenían - no sin lógica- que el problema de la industria azucarera residía en el desfasaje entre la producción de azúcar y el consumo en el mercado interno, cuando no se podía descomprimir el excedente mediante la exportación; hasta otros, particularmente la prensa norpatagónica, que criticaban abiertamente el lobby "feudal semi-esclavista y monopólico" de las regiones azucareras del norte, cuyos empresarios habrían advertido en el ingenio rionegrino una resuelta competencia para sus azúcares y que, de dejarla progresar, minaría su área de influencia y, por consiguiente, sus "súper ganancias". 5 Se retomará este tema más adelante.

Lo que queremos graficar aquí es que las causas del fracaso del ingenio San Lorenzo fueron adjudicadas mayoritariamente a agentes exógenos - por cierto, algo usual en malogros empresariales a la hora de explicar las motivaciones de una prematura interrupción-, con un particular énfasis en la capacidad de presión política de los intereses azucareros del norte. Otros escritos tomaron distancia de este tipo de premisas y optaron por enumerar posibles factores endógenos, como inconvenientes fitosanitarios, de transporte y riego, malas condiciones edáficas para los cultivos, etc. (Muñoz, 1952; Mc Callum, 1959; Alazraqui Alonso, 1964; Rey y Vidal, 1974; Vapñarsky, 1983). De todas maneras, ninguna de estas proposiciones fue el resultado de una investigación concienzuda sobre el derrotero de la Cía. Industrial y Agrícola San Lorenzo Ltda.

Para realizar un análisis de este tipo se requeriría de una investigación específica sobre el ciclo de vida de la empresa, sobre el desempeño económico-productivo de este emprendimiento agroindustrial y sobre el inestable contexto institucional, algo que excede con creces los objetivos de este trabajo. Abandonando toda pretensión de abordar la temática de manera pormenorizada, pero con el afán de arrojar luz sobre los motivos de su (¿anticipado?) cierre, hemos optado por dialogar con las versiones “acríticas”, en la medida que remarcan puntos nodales del desenvolvimiento de esta experiencia industrial, como el papel de los emprendedores, la conformación del complejo agrícola-fabril, el incremento de la producción y su abrupta caída debido a la incidencia de una plaga en los cultivos, y a la postre, el ahogo que habrían significado las disposiciones nacionales en materia azucarera, supuestamente pergeñadas por los industriales norteños para forzar la clausura del ingenio conesino.

Así, mediante el despliegue de la versión con mayor arraigo sobre los avatares de esta empresa azucarera, en primer lugar, y como segundo paso la contraposición y el diálogo crítico a partir de datos e información no consultada hasta el momento, en este primer abordaje académico sobre la temática nos ocuparemos de aristas claves del devenir del emprendimiento y propondremos explicaciones que, si acaso deberán ser tomadas como preliminares, ciertamente estarán fundamentadas en datos empíricos, esperando otorgar mayor complejidad al estudio de esta experiencia agrícola-fabril norpatagónica. Consideramos relevante el análisis de este caso en particular puesto que, a lo largo del siglo XX, se planteó en reiteradas oportunidades la posibilidad de desarrollar la agricultura remolachera como complemento de la caña de azúcar, en pos de atemperar los altibajos de la producción cañera y propender a alcanzar un modelo azucarero sustentable, con mayor aprovechamiento de subproductos y con una mayor diversificación agrícola. Asimismo, se busca sumar a la 
reflexión sobre las implicancias que posee la implantación de un modelo agrícola-fabril en regiones periféricas, sin un pasado industrial y con una agricultura incipiente reducida a cultivos tradicionales.

Las fuentes principales en las que hemos apoyado esta investigación fueron estadísticas oficiales y privadas, balances generales de la empresa, medios de prensa de tirada nacional y regional e informes técnicos de época. En definitiva, se busca llenar un notorio vacío dentro de la historiografía azucarera argentina y abrir nuevas perspectivas para analizar este importante renglón productivo del Río Negro territoriano.

\section{VERSIONES SOBRE EL AUGE Y EL FRACASO}

La S.A. Compañía Industrial y Agrícola San Lorenzo Ltda. (en adelante CIASL) fue fundada en 1927. Tan solo dos años después, el ingenio dio su primera hornada de azúcar. Fue uno de los emprendimientos agroindustriales más importantes de la Patagonia y en su rubro específico -el azúcar de remolacha- el más perdurable del país. ${ }^{6}$ La creación de esta empresa se vincula con la labor de Benito L. Raggio, miembro de una acaudalada familia de comerciantes de la ciudad de Buenos Aires. Luego de regresar al país tras una estancia de estudios en Europa, Raggio comenzó a trabajar en un emprendimiento productivo para impulsar la fabricación de azúcar de remolacha en Argentina. En estrecha colaboración con Juan Pegasano, adquirió tierras en el norte de la Patagonia, sobre la margen derecha del río Negro, y juntos fundaron las colonias San Lorenzo, donde se instaló posteriormente la fábrica; La Luisa y San Juan. ${ }^{7}$ A esas colonias se sumaron otras plantaciones en Valcheta y en zonas cercanas a Viedma, capital del Territorio Nacional de Río Negro. Se habían reunido para financiar este emprendimiento a 65 accionistas, todos inversores de Buenos Aires, Bahía Blanca y Viedma.

Avanzada la década de 1920, se realizaron los estudios de suelos y, al reconocer la aptitud de los terrenos para el cultivo de la remolacha, comenzaron con los preparativos para instalar el ingenio con maquinarias Skoda importadas de Checoslovaquia, líderes en la fabricación de equipos para la industrialización de la remolacha. Se construyeron edificios, galpones, talleres, viviendas, almacenes y demás reparticiones para acoger a una creciente población. Finalmente, el 30 de mayo de 1929, se inauguró oficialmente el ingenio con la presencia de autoridades del gobierno nacional y territoriano, de ciudades como Carmen de Patagones y Bahía Blanca, representantes del Ferrocarril Sud, y reconocidos comerciantes de la región y de la Capital Federal, contando con amplia cobertura de la prensa. ${ }^{8}$

Entretanto, se expandieron las plantaciones de remolacha por medio de riego mecánico, a las que se sumó otra área de secano en Colonia Frías, cerca de Gral. Conesa. Basados en estudios realizados por la Estación Experimental Cinco Saltos (Alto Valle del Río Negro), por entonces en manos de capitales británicos del Ferrocarril Sud, se aseveraba que el rendimiento cultural de los tubérculos sacarinos era superlativo en esas áreas, inclusive más elevado que en los complejos remolacheros de Europa, los más adelantados en la materia. Según las afirmaciones del hijo de Benito Raggio años después, el ingenio San Lorenzo era el primer paso de un emprendimiento industrial más ambicioso, puesto que se tenía prevista la erección de otras fábricas para alcanzar una producción de azúcar y derivados como alcohol y alimentos para ganado, que pudieran abastecer a la región norpatagónica y zonas linderas como el sur del área pampeana y la región cuyana. Es más, se señaló como el "gran error" que sentenció su destino el haber declarado la magnitud de este proyecto, con ingenios en Choele-Choel y Viedma, en el valle medio e inferior del río Negro, además de un cuarto en la localidad de Balcarce, al sur de la provincia de Buenos Aires. ${ }^{9}$ Todo esto habría desatado "el enojo del poderoso monopolio del azúcar del norte" inquieto porque, de concretarse dicha empresa, sufriría el desplazamiento de las plazas comerciales del centro del país en manos de la novel producción azucarera patagónica. (Luna, 2007, pp. 25-26).

El crecimiento de la planta fabril y sus requerimientos de trabajadores se tradujo en el aumento poblacional de las colonias y de la propia localidad de General Conesa, donde se instalaron centenas de familias, edificios 
públicos y comercios de diversa índole. Contingentes de inmigrantes procedentes, en su mayoría, de Europa del Este -hábiles en el cultivo de la remolacha-, lo mismo que trabajadores de otras provincias en épocas de zafra-inclusive algunos norteños conocedores del proceso de fabricación de azúcar-fueron atraídos por este emprendimiento agroindustrial.

La necesidad de contar con transporte barato para el traslado de la producción -luego de frustrarse la construcción de un ramal del Ferrocarril Sur y, posteriormente, los proyectos aprobados por el PEN para trazar un tendido dependiente del Estado-, obligó a la CIASL a hacerse cargo de la construcción de un ramal desde la línea troncal del ferrocarril estatal y acreditar, posteriormente, la devolución de parte del gobierno en concepto de fletes y transporte de insumos y producción. El tendido de $107 \mathrm{~km}$ de trocha angosta se construyó desde la estación Lorenzo Vintter hasta Colonia San Juan, pasando por el ingenio, con una estación en el casco urbano de Gral. Conesa. El tren económico favoreció no sólo el traslado de la materia prima y del azúcar, sino también de pasajeros y mercaderías diversas en las colonias. Asimismo, la empresa se hizo cargo de la construcción de obras de riego por elevación mecánica de las aguas del río.

La producción de remolacha se extendió a zonas aledañas a Viedma y Río Colorado, en territorio rionegrino, y en la zona sur de Buenos Aires, alcanzando una superficie aproximada de 3.500 hectáreas. Dos años después, en 1935, se obtuvo la mayor cosecha, con una producción cercana a las 5.000 toneladas de azúcar, más de la mitad de la capacidad productiva de la fábrica. ${ }^{10}$ Empero, toda esta prosperidad fue disminuyendo en las zafras siguientes a partir del impacto de una enfermedad en los sembradíos de remolacha. Para encontrar una pronta solución, la empresa se vio obligada a contratar personal técnico del extranjero, mientras recurría a la provisión de materia prima desde zonas más alejadas. Una vez identificada la forma de contrarrestar la plaga, y tras un año de paralizar la fábrica, se retomaron las labores en 1940, aunque lejos de las cosechas más exitosas de mediados de la década anterior. Un nuevo imponderable tuvo lugar a mitad de la zafra con la explosión de una caldera, dando por tierra con la campaña en curso.

En paralelo, se discutía en el Congreso Nacional el proyecto de ley presentado por el PEN sobre regulación de la industria azucarera al que hemos hecho referencia, que incluía la creación de la Junta Reguladora del Azúcar y contemplaba, entre otras medidas, la fijación de cupos de elaboración a todos los ingenios del país en función del consumo anual prorrateado entre las diferentes zonas productoras. Esta norma, que fue aprobada en la cámara de Senadores, establecía una cuota de 2.000 toneladas anuales de azúcar para Río Negro contra las casi 5.000 que había logrado producir en su zafra récord de 1935. Pero no logró superar el tratamiento en Diputados, donde encontró la sostenida oposición de los representantes santafesinos y correntinos, en tanto provincias con producción azucarera afectadas por la ley, incluidos parte de los intereses tucumanos por considerar que favorecía a Salta y Jujuy, a los cuales se unieron representantes del socialismo y otros grupos de la oposición.

Aun cuando no tenían representantes en el Congreso Nacional, también se expresó la situación de los emprendimientos industriales en los territorios nacionales de Chaco y Río Negro. Todos ellos se consideraban seriamente afectados por la fijación de topes máximos de producción, aduciendo un "localismo exagerado del Norte" que desconocía las inversiones realizadas en lugares ubicados a más de $2.500 \mathrm{~km}$ de la principal región cañera, como el valle rionegrino, donde se pagaba el azúcar norteño a precios elevados por los costos del flete (La Industria Azucarera, 1939).

Como ya se mencionó, sectores políticos, comerciales y periodísticos de la región, así como algunos medios gráficos de Buenos Aires y Bahía Blanca, atribuyeron este hecho a la presión que "el monopolio cañero" de las provincias del norte ejercía sobre el gobierno central. ${ }^{11}$ Los argumentos utilizados por parte de los directivos de la CIASL y las autoridades rionegrinas ante los poderes nacionales para intentar modificar el proyecto, insistían en que se les elevara el cupo asignado a $6.000 \mathrm{t}$ como mínimo, en tanto el mercado consumidor al que aspiraban aprovisionar - la zona más austral del país, incluyendo el sur de Mendoza-, consumía nada menos que 80.000 t anuales. De esta manera, lograrían asegurarse la cobertura de una porción de la demanda sin lesionar directamente a las redes de comercialización de Buenos Aires. 
Ante este cúmulo de acontecimientos adversos, más una inesperada enfermedad de Raggio, el directorio de la Compañía tomó la decisión de terminar con la explotación en 1941. Se liquidaron los bienes de la sociedad, las maquinarias fueron adquiridas por industriales uruguayos mientras que los edificios y el resto de las instalaciones quedaron en poder del Centro Azucarero Regional del Norte Argentino (entidad representativa de los ingenios azucareros de Salta y Jujuy) que, según testimonios, exigió la demolición de los mismos y el compromiso de no volver a establecer otro ingenio de remolacha en el lapso de diez años. Las plantaciones con tubérculos fueron suplantadas por alfalfa y otros cultivos en menor escala, mientras que la mayor parte de los habitantes migraron del lugar. Según señalan las crónicas, a fines del año 1949, con el fallecimiento de Raggio en plenas labores para relanzar el cultivo extensivo de remolacha, la aspiración de producir azúcar en la Patagonia se canceló. ${ }^{12}$ Años más tarde, en 1958, intereses influyentes de la región retomaron el proyecto, pero no llegaron a concretarlo. ${ }^{13}$

Una vez expuesta la versión con mayor apego en los escritos históricos y en el imaginario social norpatagónico sobre el devenir de esta empresa - por cierto, con un tono expresamente descriptivoproponemos abordar la temática a partir de algunos elementos presentados que permitan una mejor comprensión de esta experiencia productiva en el valle medio e inferior del río Negro.

\section{UNA MIRADA SOBRE LOS EMPRESARIOS Y ESTE PARTICULAR PROYECTO INDUSTRIAL}

Se señaló que Benito Raggio y Juan Pegasano estuvieron íntimamente ligados al proceso de configuración y concreción del ingenio remolachero San Lorenzo. ${ }^{14}$ Luego de sumar las voluntades de inversores de Buenos Aires, Bahía Blanca y Viedma, reunieron el capital inicial y fundaron la compañía en 1927. Al respecto, surge el interrogante sobre los motivos por los cuales empresarios de diferentes rubros y procedencias se embarcaron en un proyecto agrícola-fabril prácticamente desconocido en la Argentina en casi todos sus aspectos, salvo ensayos con cultivos experimentales, y cuando el coetáneo emprendimiento sanjuanino se encontraba todavía en proceso de concreción.

Si repasamos los primeros directorios de la firma, es evidente que una mayoritaria porción tenía su raigambre empresarial en el ámbito del comercio, la intermediación de "productos del país" (cueros, ganado ovino y bovino, productos agrícolas), la compra/venta de tierras y las finanzas y, sólo en casos puntuales, se evidenciaba alguna ligazón con emprendimientos industriales (véase Apéndice Tabla 1). ${ }^{15}$ Esto no quiere decir, sin embargo, que haya existido una total desconexión con el rubro azucarero. Para entonces Raggio, además de su pertenencia a la firma comercial mayorista familiar, había construido lazos previos en la comercialización del dulce, desempeñándose a inicios de los años 1920 en el ramo de comisiones y consignaciones de azúcares, alcoholes y arroz bajo la razón social Benito L. Raggio, con su casa central en Buenos Aires. En momentos previos a la formación de la CIASL, ya operaba con azúcar de los ingenios norteños en ciudades como Mendoza, Córdoba, San Luis, Paraná y Bahía Blanca, a las que se agregaron nuevas filiales en Rosario, Santa Fe y La Plata. Una vez en marcha la fabricación de azúcar en San Lorenzo, sumó a Mar del Plata como un asiento más de sus operaciones comerciales (La Industria Azucarera, 1920-1930).

Tampoco dejan de llamar la atención los motivos por los que se escogió el Valle Medio e Inferior del río Negro para emplazar el ingenio y los cultivos, en vez de un área más cercana a su zona de influencia como podría ser el sudeste de la provincia de Buenos Aires, con mayor conectividad por medio de tendidos férreos y caminos, y donde ya se había introducido el cultivo remolachero en parcelas experimentales. ${ }^{16}$ 
TABLA 1

Miembros del directorio de CIASL (1926-1940)

\begin{tabular}{|c|c|c|c|c|c|c|c|c|c|c|c|c|c|c|c|}
\hline Integrantes & $\stackrel{\text { ֻั }}{\leftarrow}$ & ু & 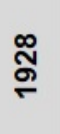 & ণั & ஓ్ల & 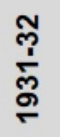 & $\begin{array}{l}\text { ஜூ } \\
\text { ஸु } \\
\text { లु }\end{array}$ & 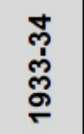 & 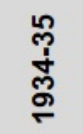 & 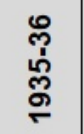 & 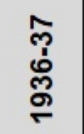 & 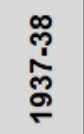 & 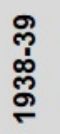 & $\begin{array}{l}\text { 옴 } \\
\text { ᄋ్ } \\
\text { ळ }\end{array}$ & $\begin{array}{l}\text { 广̛ } \\
\text { ơ } \\
\stackrel{+}{-}\end{array}$ \\
\hline Pegasano, Juan & $\mathrm{P}$ & $\mathrm{P}$ & $\mathrm{s} / \mathrm{d}$ & $\mathrm{P}$ & $\mathrm{P}$ & $\mathrm{P}$ & $\mathrm{P}$ & $\mathrm{P}$ & $\mathrm{P}$ & $\mathrm{P}$ & $\mathrm{P}$ & $\mathrm{P}$ & & & \\
\hline Maglione, Francisco & VP & VP & $\mathrm{s} / \mathrm{d}$ & $\mathrm{VP}$ & VP & & & & & & & & & & \\
\hline Raggio, Lorenzo & $\mathrm{D}$ & $\mathrm{D}$ & $\mathrm{s} / \mathrm{d}$ & $\mathrm{D}$ & & & & & & & & & & & \\
\hline Terrabusi, Humberto & $\mathrm{D}$ & $\mathrm{D}$ & $\mathrm{s} / \mathrm{d}$ & $\mathrm{D}$ & $\mathrm{D}$ & & & & & & & & & & \\
\hline Raggio, Benito L. & $\mathrm{D}$ & $\mathrm{D}$ & $\mathrm{s} / \mathrm{d}$ & $\mathrm{D}$ & $\mathrm{D}$ & $\mathrm{D}$ & $\mathrm{D}$ & $\mathrm{D}$ & $\mathrm{D}$ & $\mathrm{D}$ & $\mathrm{D}$ & $\mathrm{D}$ & $\mathrm{D}$ & $\mathrm{D}$ & $\mathrm{D}$ \\
\hline Olaciregui, Ramón & $\mathrm{D}$ & D & $\mathrm{s} / \mathrm{d}$ & $\mathrm{D}$ & D & $\mathrm{D}$ & $\mathrm{s} / \mathrm{d}$ & & D & D & $\mathrm{D}$ & D & & & $\mathrm{D}$ \\
\hline Etcheverrigaray, Fabián & $\mathrm{D}$ & $\mathrm{D}$ & $\mathrm{s} / \mathrm{d}$ & $\mathrm{D}$ & $\mathrm{D}$ & $\mathrm{D}$ & $\mathrm{s} / \mathrm{d}$ & & & & & & & & \\
\hline Mosto, Alfredo & $\mathrm{D}$ & $\mathrm{D}$ & $\mathrm{s} / \mathrm{d}$ & & & $\mathrm{D}$ & $\mathrm{s} / \mathrm{d}$ & $\mathrm{D}$ & $\mathrm{D}$ & $\mathrm{D}$ & $\mathrm{D}$ & & & & \\
\hline Antonini, Enrique & $\mathrm{D}$ & $\mathrm{D}$ & $\mathrm{s} / \mathrm{d}$ & & & & & & & & & & & & \\
\hline Repetto, Luis Andrés & & & & & & & & VP1 ${ }^{\circ}$ & VP1 ${ }^{\circ}$ & VP1 $1^{\circ}$ & VP1 ${ }^{\circ}$ & VP1 ${ }^{\circ}$ & $P$ & $P$ & \\
\hline Luchinetti, Arnaldo & & & & & & & & $\mathrm{VP} 2^{\circ}$ & $\mathrm{VP}^{\circ}$ & $\mathrm{VP} 2^{\circ}$ & $\mathrm{VP}^{\circ}$ & $\mathrm{VP}^{\circ}$ & VP & VP & $\mathrm{P}$ \\
\hline Abaciregui, Ramón & & & & & & & & $\underline{v}$ & & & & & & & \\
\hline Camuyrano, Américo & & & & & & & & $\mathrm{V}$ & $\mathrm{D}$ & $\mathrm{D}$ & $\mathrm{D}$ & $\mathrm{D}$ & $\mathrm{D}$ & $\mathrm{s} / \mathrm{d}$ & \\
\hline Giménez Melo, Nereo & & & & & & & & & & & & & $\mathrm{D}$ & $\mathrm{s} / \mathrm{d}$ & $\mathrm{VP}^{\circ}$ \\
\hline Lamesa, Domingo & & & & & & & & & & & & & $\mathrm{D}$ & $\mathrm{s} / \mathrm{d}$ & $\mathrm{D}$ \\
\hline Minuto, José & & & & & & & & & & & & & D & $\mathrm{s} / \mathrm{d}$ & VP2 $2^{\circ}$ \\
\hline Holzer, Juan & & & & & & & & & & & & D & & & \\
\hline Fliess, Alois & $\mathrm{S}$ & $\mathrm{S}$ & $S$ & $\mathrm{~S}$ & $\mathrm{~S}$ & S & $\mathrm{S}$ & $\mathrm{S}$ & $\mathrm{S}$ & $\mathrm{S}$ & $\mathrm{S}$ & $\mathrm{S}$ & $\mathrm{S}$ & S & S \\
\hline
\end{tabular}

Fuente: Elaboración propia a partir de Guía de Sociedades Anónimas (1927-1942)

(P) Presidente; (VP) Vicepresidente; $\left(\mathrm{VP} 1^{\circ}\right.$ ) Vicepresidente primero;

$\left(V_{P} 2^{\circ}\right)$ Vicepresidente segundo; (D) Director; (V) Vocal; (S) Síndico.

En este punto se debe recordar la concesión que se le otorgó a Pedro Riccheri en 1910 para erigir fábricas remolacheras en el territorio provincial bonaerense. Desconocemos si esta licencia representó una limitante insalvable para que otros emprendedores pudieran erigir un ingenio azucarero en Buenos Aires y no se pudo gestionar ante los poderes provinciales alguna medida que pudiera franquear dicha exclusividad, o si acaso existió la posibilidad de una asociación no concretada, luego de que Riccheri fracasara reiteradas veces en reunir el capital para su emprendimiento remolachero en la provincia. ${ }^{17}$ Lo cierto es que la localización para organizar un complejo agroindustrial en el Territorio Nacional de Río Negro no estaba exenta de atractivos. Si se comprobaba la aptitud de suelos a lo largo de los ríos Negro o Colorado para el desarrollo de la remolacha azucarera, se correría con una apreciable ventaja por la proximidad de los mercados que se pretendía ganar y por la posibilidad de sortear la carga impositiva provincial que hubiera pesado si se radicaba en algún punto de Buenos Aires (por lo menos hasta la unificación de los impuestos internos en 1935). En tal sentido, si la opción era un área territoriana, sería fundamental una buena conexión terrestre con las principales plazas comerciales y con las zonas adyacentes proveedoras de la materia prima.

Los estudios que señalaron las ventajas de los suelos norpatagónicos para el cultivo de este sacárido -y que influyeron en los promotores del proyecto azucarero- los llevó a cabo el Ing. Agr. Juan Barcia Trelles (director de la Estación Agronómica de Cinco Saltos, dependiente del Ferrocarril Sud) quien en 1920 inició las siembras de remolacha azucarera en el Alto Valle del río Negro. Según sus palabras, desde 1918 albergaba perspectivas halagüeñas sobre este cultivo, pero los resultados excedieron todo pronóstico. ${ }^{18}$ De este modo, señaló las ventajas de instalar una fábrica de azúcar sobre las márgenes del río Negro que estuviera conectada con los puertos y centros urbanos, para ofrecer azúcar barato para el consumo y para insumo en la elaboración de dulces y conservas con productos del Alto Valle.

Los cultivos experimentales habían dado buenos rendimientos mediante el uso de semillas de variadas especies y modernas técnicas de cultivo. ${ }^{19}$ Además, la complementación entre fruticultura y producción 
azucarera sin dudas podría haber representado un estímulo central en la generación de una industria de conservas a menores costos. Sin embargo, las características mismas del emprendimiento industrial que finalmente se concretó, sumado al perfil comercial/financiero de los miembros del directorio de CIASL, permiten suponer que el objetivo no se reducía a lo antedicho, sino que se buscó resueltamente producir azúcar para el consumo y colocarla en las mayores plazas comerciales de la región sudpampeana y norpatagónica. Así, se podría abastecer la demanda regional a bajos costos basados en las perspectivas de altos rendimientos agrícola/industriales y menores precios de fletes que el azúcar norteño, llegando a Viedma, Carmen de Patagones, Bahía Blanca, Mar del Plata y los puertos meridionales, mientras que hacia el poniente se podrían remontar hasta Neuquén o, hacia el norte, alcanzar el Territorio Nacional de La Pampa y la parte meridional de Buenos Aires. ${ }^{20}$

En otras palabras, los socios primigenios tuvieron un razonable interés por integrarse "hacia atrás", ingresando en la elaboración de azúcar y consolidando las líneas de comercialización ya construidas, donde la ciudad-puerto de Bahía Blanca podía disputarle el lugar, como eje de distribución de azúcar, a las redes de comercio comandadas por las principales casas de Buenos Aires y Rosario. ${ }^{21}$ Empero, desde sus orígenes, esta estrategia no habría funcionado como en un principio se planificó.

\section{ENTRE PROMESAS INCUMPLIDAS Y PROYECCIONES DESACERTADAS}

Conocidas las ventajas productivas del norte patagónico para la explotación agrícola, paulatinamente se fue definiendo la zona más conveniente para favorecer el cultivo de peras y manzanas en pequeñas explotaciones familiares en el Alto Valle del río Negro, con una fuerte incidencia del capital británico que controló el transporte y la comercialización de la fruta a través del Ferrocarril Sud (Bandieri y Blanco, 1998). No obstante, el conocimiento de las condiciones productivas del Valle Medio e Inferior para un emprendimiento de azúcar de remolacha era todavía insuficiente. Sobre este punto es preciso recordar que el mentado estudio de Barcia Trelles, si acaso proponía explícitamente la explotación industrial de este sacárido por sus resultados prometedores, basaba su consideración en datos obtenidos en el Alto Valle, en parcelas experimentales reducidas y controladas; es decir, en condiciones muy diferentes al entorno donde finalmente operó el ingenio San Lorenzo.

Desde el punto de vista estratégico, esta proyección se recostaba sucintamente en: a) energía hidráulica a bajo costo mediante el aprovechamiento de los rápidos y saltos de agua; b) combustible económico por su cercanía y conexión ferroviaria con el área petrolera de Plaza Huincul; c) facilidades de comunicación con los centros de consumo por el acceso a los tendidos troncales de las empresas ferroviarias; d) abundante agua provista por el canal con toma en el río Negro; e) caleras cercanas, para extraer insumos necesarios en la fabricación. De las cinco ventajas enunciadas por Barcia Trelles (1922, pp. 23-24), la zona donde se emplazó y operó el ingenio en la zona del Valle Medio contaba solamente con la última. En efecto, no se disponía de saltos ni tomas sobre el cauce del río que se pudieran aprovechar, no existía una conexión ferroviaria para aprovisionarse de combustible e insumos ni para trasladar la producción, ni se habían construido aún las obras de regadío.

Cabe consignar que, en 1926, el gobierno nacional había aprobado la ejecución de obras para construir un canal de $75 \mathrm{~km}$ con el objeto de beneficiar con riego a todo el valle conesino y estimular la explotación de esas tierras. De igual modo, se había votado la concesión al Ferrocarril Sud para establecer una línea férrea de poco más de $300 \mathrm{~km}$ a lo largo de los Valles Medio e Inferior, que uniera Carmen de Patagones con Darwin, y así conectar definitivamente la cordillera con la costa atlántica a lo largo del río Negro (Congreso Nacional, 1926). Empero, los efectos de la crisis de 1930 en el erario nacional frenaron la construcción de este tendido. Posteriormente, el Congreso de la Nación denegó la concesión al Ferrocarril Sud. ${ }^{22}$ Como resultado, durante 
esos años no se construyeron ni el tendido ferroviario que conectaría la zona del ingenio con la línea troncal, ni tampoco las obras de riego que favorecerían el desarrollo de los cultivos. ${ }^{23}$

En tal sentido, la construcción del ramal de trocha angosta efectuada por la CIASL fue nada menos que el producto de una necesidad imperiosa por contar con un medio de transporte económico, indispensable para acarrear la materia prima y la producción de azúcar a los centros de distribución y consumo. También explica que este tendido se haya inaugurado recién en 1933, a cuatro años de la zafra inaugural. La CIASL convino con la empresa Ferrocarriles del Estado la construcción con capitales propios de un ramal de $107 \mathrm{~km}$ de extensión desde la Estación Gral. Lorenzo Vintter hasta la Estación San Juan. La firma estatal proveyó los materiales necesarios y se comprometió a devolver el costo de la obra a la sociedad azucarera, acreditándole fletes de remolacha y de productos enviados desde y hacia el ingenio. Si bien esa partida se asentaba en el activo de la firma, representaba una cuantiosa erogación no planificada de dinero y una maniobra sobremanera arriesgada, en tanto sería exitosa sólo si se cumplía íntegramente con el acuerdo. Sin entrar en detalles, podemos mencionar que no ocurrió de ese modo. ${ }^{24}$

Esta falta de transporte y riego que se esperaba la realizara el Estado nacional, representó un escollo desde el principio: las máquinas adquiridas en Europa tuvieron que ser trasladadas en camiones a través de $100 \mathrm{~km}$ por caminos de tierra desde el tendido troncal del ferrocarril hasta San Lorenzo. Por los mismos medios se transportó la materia prima, los insumos y la escasa producción por el espacio de un lustro, hasta la definitiva inauguración del ramal ferroviario construido por la empresa. Asimismo, se hizo necesaria la construcción de obras de riego por elevación mecánica de las aguas del río mediante centrífugas, lo que implicó una alta inversión inicial en infraestructura indispensable.

\section{Puesta en marcha y colapso imprevisto}

La fábrica azucarera se inauguró en 1929, pero las dos primeras zafras fueron experimentales, necesarias para poner a punto la maquinaria. En la Tabla 2 se puede observar que, de campañas casi simbólicas de $1929 / 1930$, se fue acondicionando el funcionamiento de la unidad productiva con un incremento en las cosechas de 1932 y 1933, cuando las vías férreas fueron conectando paulatinamente las áreas de cultivo y se sortearon las dificultades de parte de los agricultores para conseguir el punto justo de maduración de la remolacha en la época de zafra. La elaboración describió una curva ascendente hasta alcanzar su pico máximo histórico en 1935, con casi 5.000 toneladas, a la par que se diversificó la producción, elaborando diferentes tipos de azúcares de acuerdo a la demanda (refinado y/o granulado) y se agilizó la colocación de los productos (sea para consumo directo o como insumo para otras actividades). 
TABLA 2

Elaboración de remolacha, azúcares y rendimiento de la CIASL, 1929-1940 (en toneladas)

\begin{tabular}{|r|r|r|r|r|r|r|}
\hline Zafras & $\begin{array}{c}\text { Remolacha } \\
\text { molida }\end{array}$ & $\begin{array}{r}\text { Refinado y } \\
\text { Pilé }\end{array}$ & $\begin{array}{c}\text { Granulado } \\
\text { y Molido }\end{array}$ & $\begin{array}{c}\text { Crudo y } \\
\text { Bajos } \\
\text { Productos }\end{array}$ & $\begin{array}{l}\text { Total azúcar } \\
\text { producido }\end{array}$ & $\begin{array}{l}\text { Rendimiento } \\
\text { industrial } \%\end{array}$ \\
\hline 1929 & $\mathrm{~s} / \mathrm{d}$ & 50 & $\mathrm{~s} / \mathrm{d}$ & $\mathrm{s} / \mathrm{d}$ & 50 & $\mathrm{~s} / \mathrm{d}$ \\
\hline 1930 & $\mathrm{~s} / \mathrm{d}$ & 872 & $\mathrm{~s} / \mathrm{d}$ & $\mathrm{s} / \mathrm{d}$ & 872 & $\mathrm{~s} / \mathrm{d}$ \\
\hline 1931 & 2.856 & 382 & $\mathrm{~s} / \mathrm{d}$ & $\mathrm{s} / \mathrm{d}$ & 382 & 13,4 \\
\hline 1932 & 10.973 & 960 & 491 & --- & 1.451 & 13,2 \\
\hline 1933 & 17.000 & 1.863 & 268 & --- & 2.131 & 12,5 \\
\hline 1934 & 21.661 & 2.906 & 261 & --- & 3.167 & 14,6 \\
\hline 1935 & 32.812 & 4.771 & 130 & --- & 4.901 & 14,9 \\
\hline 1936 & 16.782 & 2.104 & 216 & --- & 2.320 & 13,8 \\
\hline 1937 & 8.633 & 1.008 & --- & 37 & 1.044 & 12,1 \\
\hline 1938 & 3.333 & 372 & --- & 19 & 391 & 11,7 \\
\hline 1939 & no produjo & no produjo & no produjo & no produjo & no produjo & no produjo \\
\hline 1940 & 19.816 & 2.145 & 41 & 40 & 2.226 & 11,2 \\
\hline
\end{tabular}

Fuente: elaboración propia a partir de datos de Schleh (1944, pp. 212-213).

Sin ponderar la situación económica-financiera de la empresa, a simple vista todo parecía marchar sobre rieles, con un evidente incremento de la producción y la ampliación de la superficie de cultivo. Sin embargo, la tendencia cambió de manera abrupta. A partir de 1936, una grave enfermedad diezmó las plantaciones de remolacha en un breve lapso y, como consecuencia, impactó en el normal desenvolvimiento económico de la empresa, en la medida en que se encontró con un ingenio en marcha sin materia prima para procesar. Las consecuencias del "marchitamiento amarillo" (yellow wilt) pueden visualizarse en el brusco descenso de la cantidad de remolacha elaborada (Tabla 2). Así, tras la zafra récord de 1935, la molienda alcanzó sólo al 51\% del año precedente, continuó con una caída del 50\% en 1937 respecto del año anterior, y descendió al 38\% en la zafra 1938. Ante esta crítica situación, la firma decidió detener los difusores de la fábrica en 1939, prefiriendo el paro antes que correr con los costos de poner en funcionamiento un ingenio con alta capacidad ociosa.

Sin ánimo de entrar en precisiones técnicas ni relatar las peripecias por las que transitó el combate contra la plaga, podemos indicar que el directorio dispuso lo necesario para que se estudiara la enfermedad y se buscara una solución expeditiva. Se contrató personal técnico de la Escuela Superior de Agronomía de Holanda, como J. Huyskes, y luego al estadounidense C. Bennett. Asimismo, se contó con el asesoramiento del ingeniero danés C. Munck, de la empresa del Ferrocarril Sud, especialista en plagas y conocedor directo de la experiencia norteamericana en su combate contra el Curly Top, una enfermedad con similares características que había azotado cuatro años antes los sembradíos norteamericanos. La premura por identificar el origen de la plaga y encontrar el procedimiento adecuado para revertirla derivó, como lógica consecuencia, en conclusiones apresuradas y diagnósticos disímiles. Huyskes atribuyó el problema sanitario a una deficiencia de los suelos y a la mala aplicación del riego, mientras que Bennett -en colaboración con Munck- lo adjudicó a un virus filtrable trasmitido a la remolacha por un insecto vector. ${ }^{25}$

Mientras tanto la CIASL, con el objetivo de mantener en funciones el ingenio, buscó zonas donde la plaga no se hubiera manifestado y donde los agricultores estuvieran dotados de experiencias previas en el cultivo del sacárido. Se resolvió celebrar contratos para la provisión de materia prima con productores del interior de 
la provincia de Buenos Aires y se arrendó un campo colindante con la Estación Experimental de Mechongué, perteneciente al Ferrocarril Sud (próxima a Lobería, en el sudeste bonaerense), para utilizarlo como campo de ensayos y asesoramiento a los agricultores. Toda esta readecuación sobre la marcha para asegurar el mayor abastecimiento posible de remolacha significó una importante erogación extra de las arcas de la CIASL, sobre todo por la distancia que debían cubrir las remesas de materia prima. En efecto, las nuevas áreas productoras se encontraban en lugares alejados como Pedro Luro, Tres Arroyos y Lobería, distantes nada menos que a 350 , 450, e incluso a $700 \mathrm{~km}$ respectivamente (Instituto Agrario Argentino, 1946, p. 90). Si acaso la operación fue factible gracias a un esquema tarifario sobre "flete especial de fomento combinado" acordado por la CIASL, el Ferrocarril Sud y los FFCC del Estado, resulta incuestionable lo antieconómico de esta alternativa de aprovisionamiento.

De acuerdo con la información recabada en las estadísticas industriales, si en 1935 el valor de una tonelada de remolacha cultivada directamente por la empresa y una comprada a agricultores locales era prácticamente análogo, en 1937, a causa de la distancia y del flete, la materia prima de terceros incrementó su costo en un 40\% más que la propia. En 1938 su valor retornó a una relativa equivalencia, cuando se dejó de comprar remolacha allende las fronteras territorianas y se volvió a la provisión de los agricultores locales (República Argentina, 1936, 1938, 1939b). Con todo, no quedan claros los motivos por los que se retornó al suministro local cuando aún no se habían reactivado los terrenos afectados por la plaga. Esto derivó en el descenso de los volúmenes de remolacha procesada e incluso en la paralización de la fábrica.

Además del costo de flete que, como adelantamos, fue parcialmente solventado por un esquema tarifario ad $h o c$, un factor que debe ser estudiado con mayor profundidad es la poco entusiasta respuesta de los agricultores bonaerenses ante la demanda del ingenio rionegrino en las campañas inmediatas a la aparición de la plaga. Según recordara años más tarde el diputado por Buenos Aires José Liceaga (uno de los defensores de la reinstalación en el país de la industria azucarera con base en la remolacha), los agricultores del sudeste de Buenos Aires, a diferencia de los ubicados en el extremo sur de la provincia -más próximos al ingenio-, desistieron prontamente de cultivar remolacha pese a contar con una inesperada demanda que les habría proporcionado ingresos seguros. Sucedió que, a pesar del apremio por aprovisionarse de remolachas, la CIASL mantuvo en vigencia un sistema de pago por la entrega de tubérculos mediante el cual se determinaba la pureza de la materia prima -y el consiguiente desembolso monetario- en el mismo ingenio y no en las estaciones de carga ubicadas en los terrenos de cultivo. Debido a las inevitables pérdidas de sacarosa contenida en las raíces una vez efectuada la cosecha, este esquema beneficiaba a los proveedores colindantes y perjudicaba sobremanera a los más alejados al descender el rendimiento de la materia prima durante el extenso trayecto hasta el ingenio. Posiblemente, esta situación generó suspicacias entre los agricultores del sudeste bonaerense, al encontrarse con una demanda cautiva, pero con cosechas poco atractivas por los escasos márgenes de utilidades finales. ${ }^{26}$

Las estadísticas corroboran, por lo menos en parte, dichas afirmaciones. En 1937, la totalidad de las tierras censadas en la provincia de Buenos Aires con cultivos remolacheros se ubicaban en el partido de Villarino (al sur de la provincia, en las adyacencias de Pedro Luro) lo que indicaría que las restantes áreas desistieron rápidamente de cultivar las raíces sacarinas de manera extensiva (República Argentina, 1939a, p. 193). Estas cifras permiten, a la vez, relativizar las versiones que adjudican una sostenida expansión de los cultivos en las diferentes áreas -inclusive en los momentos más duros de la crisis- llegando a atestiguar la subsistencia de más de 1.000 ha en $1937 .{ }^{27}$ Dicha extensión se asemeja a las 1.400 ha que efectivamente Río Negro tuvo bajo cultivo remolachero en su zafra récord de 1935, pero distan bastante de las 780 ha que efectivamente logró mantener bajo explotación en 1937, prácticamente todas cercanas al ingenio. ${ }^{28}$ Lo cierto es que los volúmenes de remolacha descendieron de manera abrupta procesando, en el año previo a la paralización transitoria de la fábrica, lotes notoriamente reducidos en comparación con la campaña de mayor producción. ${ }^{29}$ 
Cabe aquí un breve comentario respecto a una versión en boga sobre lo que ocurrió en las parcelas remolacheras de Río Negro. Se acostumbra a atribuir la aparición de la enfermedad a una "siembra intencional" del virus patógeno en los cultivos por parte de agentes interesados en "destruir" este emprendimiento agroindustrial. Como señaló Jaime Alazraqui (1964) en incontables oportunidades, eso nunca se llegó a probar, por lo que recomendaba reconocer que el accidente sanitario fue ocasionado por causas naturales, como suele suceder en otros cultivos extensivos, en un contexto donde la tecnología agrícola y las prácticas agronómicas impedían actuar con presteza ante un imprevisto de esas características. ${ }^{30}$

Con lo expuesto no se pretende adjudicar una razón unívoca al colapso de este emprendimiento, pues entendemos que no debe reducirse la complejidad de la experiencia histórica. Sin embargo, no se debe pasar por alto el impacto que demandó una caída del 50\% de la producción en 1936, dos zafras desastrosas en 1937/38 y la paralización de la planta fabril al año siguiente. Pese a que se logró remontar parcialmente la situación en la cosecha de 1940, las dificultades no desaparecieron del horizonte. A continuación, nuestro análisis dejará parcialmente los elementos productivos y sanitarios y pasará a abordar los factores institucionales.

\section{ZAFRAS REgULADAS Y MERCADOS RESTRINGIDOS}

Uno de los puntos que mayor relieve tomó a la hora de explicar el cierre del San Lorenzo, en 1941, fue la ínfima cuota de producción que se le adjudicó a Río Negro por parte de los que la prensa regional señalaba como "figurones feudales", que mediante convenios y proyectos de leyes intentaban ordenar el mercado azucarero, pero con el objetivo final de consolidar el funcionamiento "ultramonopolista de los ingenios salto-jujeños". ${ }^{31}$ Así, se les reclamaba a los intereses vinculados a los complejos azucareros norteños, sobre todo los de Salta y Jujuy que, en aras de adecuar la producción y la comercialización a las necesidades del consumo interno, finalmente consolidaban sus posiciones en claro detrimento del grupo de out-siders -es decir, los ingenios del nordeste y de Río Negro ubicados fuera de la histórica región productora de azúcaral otorgarles una baja cuota de participación en el mercado.

Las versiones periodísticas y las reconstrucciones históricas coincidieron al detalle sobre esta situación, ubicando en la imposición de un tope de producción bastante menor a su capacidad productiva como el "golpe de gracia" que determinó el cierre del ingenio conesino. ${ }^{32}$ Aunque esto es un tema que debería tratarse en un estudio específico, consideramos pertinente despejar confusiones y contribuir a la comprensión de este arduo periodo de regulaciones y convenios en la actividad.

Desde mediados de la década de 1920, la agroindustria azucarera argentina ingresó en una fase cargada de inconvenientes. En el frente interno, se abrió una etapa de sobreproducción de azúcar que excedió con creces la capacidad de absorción de la demanda doméstica. Esto se combinó con una abundante oferta en el mercado internacional, lo que vino a representar una seria amenaza al mercado interno. Efectivamente, pese a estar protegido por aranceles específicos a la importación, la pronunciada caída de los precios en el mercado internacional permitía que el símil extranjero sorteara la banda protectora e ingresara a competir directamente con el azúcar nacional. Todo esto generó una presión a la baja de las cotizaciones, cuyas derivaciones se sintieron no sólo en la esfera comercial sino en la faz productiva de Tucumán, principal complejo azucarero del país.

En efecto, esta provincia ingresó en un conflicto fabril-cañero inusitado hasta el momento, en el cual afloró la puja por la distribución del ingreso azucarero entre los empresarios y los cañeros independientes. En 1928, tras dos zafras conflictivas, finalmente se consensuó el arbitraje del presidente Marcelo T. de Alvear para sortear el trance. Del Laudo se desprendieron varias medidas de regulación tendientes a ordenar la actividad, como leyes limitadoras de la producción, penalidades para aquellos que sobrepasaran el cupo, garantías de molienda a cañeros y beneficios para quienes exportaran los stocks. ${ }^{33}$ En definitiva, se implementaba un 
nuevo sistema normativo que aseguraba márgenes "aceptables" de rentabilidad a la totalidad del parque industrial azucarero y, al mismo tiempo, procuraba garantizar la supervivencia del sector cañero. Sin embargo, resultó insuficiente para ordenar la actividad de manera integral. Las leyes reguladoras fueron renovadas en varias oportunidades, pero sólo se aplicaron en el espacio provincial tucumano, lo que lesionaba todo intento por distribuir equitativamente las restricciones y los beneficios para la totalidad de los productores azucareros, en tanto los otros complejos, particularmente Salta y Jujuy, continuaban trabajando sin limitaciones (Bravo y Gutiérrez, 2014, pp. 160-162).

El aumento de los costos de producción como consecuencia del Laudo llevó a robustecer la coordinación de las ventas con el fin de sostener lo más alto posible el precio del azúcar, sin ultrapasar el límite permitido por la ley nacional 8.877 de 1912, que ubicaba como tope 4 pesos los $10 \mathrm{~kg}$ en plaza de Buenos Aires, so pena de abrir la importación para forzar el descenso de las cotizaciones. Como no existía una legislación que regulara de manera general a la actividad, el sector privado consensuó sobre la necesidad de aplicar lo que Girbal-Blacha (2017) acertadamente denominó “la acción legislativa invisible”, esto es, una serie de convenios entre el conjunto de fabricantes y comercializadores con el fin de establecer límites a la producción para contrarrestar la sobreoferta y acuerdos de mercado para sostener los precios del dulce. En consecuencia, se creó el Consejo Directivo de la Industria Azucarera, ente privado encargado de fiscalizar las ventas de azúcar y asignar los precios y cupos a los diferentes ingenios, según el movimiento de las cotizaciones y la demanda de cada región. ${ }^{34}$ Dicho organismo instituyó varios acuerdos durante una década, hasta que en 1936 la producción nuevamente sobrepasó los márgenes estipulados, lo que dejó en evidencia que ni los convenios privados ni la limitación asimétrica aplicada a Tucumán bastaban para ordenar integralmente la producción y comercialización del azúcar en el mercado interno.

Durante la presidencia de Roberto M. Ortiz se conformó una Comisión, en 1937, con el objeto de estudiar el problema azucarero y proponer una legislación que solucionara definitivamente la actividad azucarera, a través de la regulación de la producción, el sostenimiento de sus factores centrales (industriales, cañeros independientes y comercializadores) y el ordenamiento del mercado para evitar fluctuaciones de los precios internos. Entre 1938 y 1939 se discutió el proyecto de ley azucarera, impulsado por el ya mencionado ministro José Padilla.

Como ya se adelantara, algunos sectores involucrados consideraron que la nueva ley favorecería a los ingenios de Salta y Jujuy, no así a los cañeros e industriales tucumanos, ni mucho menos de las otras provincias. Ciertos medios de prensa, más pesimistas, como El Atlántico del año 1939, atacaron duramente al proyecto de ley y a su redactor Padilla (de hecho lo llamaban "Proyecto Padilla", miembro de "la dinastía azucarera Nougués-Padilla") por oficiar, según su criterio, en beneficio de los monopolios salto-jujeños y en claro detrimento de los out-siders debido a los bajos cupos de producción asignados. ${ }^{35}$ Las $2.000 \mathrm{t}$ anuales que el proyecto establecía para Río Negro, como era de esperarse, generaron inmediatas reacciones. La Gobernación rionegrina -entonces a cargo de Adalberto Pagano- remitió en 1938 una nota reservada al Ministro del Interior, Dr. Diógenes Taboada, aludiendo a la desventaja en que quedaría la industria azucarera de este territorio ante el nuevo esquema regulatorio. Acompañaba a los mismos fines otra nota remitida por el directorio de la CIASL a la gobernación territoriana y a la Comisión de Agricultura del Senado de la Nación. En ambas epístolas se señalaban los problemas sufridos por el Ingenio San Lorenzo en los últimos años, situación que lo colocaba en menoscabo respecto a los demás integrantes del grupo de out-siders. En consecuencia, la CIASL solicitaba una cuota básica de industrialización de $6.000 \mathrm{t}$ anuales, enmarcando el pedido en la necesidad de cubrir el "demorado estímulo para el progreso de la Patagonia”, mientras señalaba que la parte del león se la llevaba Salta y Jujuy, por beneficiarse con una cuota proporcional más elevada. ${ }^{36}$

Luego de la revisión del proyecto en el Senado, la cuota de este grupo secundario fue incrementada, particularmente la rionegrina que se estableció en 3.500 toneladas anuales con posibilidad de ampliación (es decir, más del doble de su promedio histórico y aún más alto que el cociente de los años de mayor elaboración). Tras sendos debates luego de devuelto el proyecto a la Cámara Baja, en septiembre de 1939 finalmente fracasó 
este intento de legislación nacional de la actividad azucarera. ${ }^{37}$ Se retomaron los convenios privados como única alternativa posible y con el tiempo se logró su renovación, por cierto, no sin conflictos intrasectoriales.

En conclusión, a contrapelo de las versiones más arraigadas, no gravitó una legislación azucarera a nivel nacional que impusiera un cupo restrictivo de $2.000 \mathrm{t}$ ni de $3.500 \mathrm{t}$ al ingenio San Lorenzo. Si a la empresa no le satisfizo el margen de participación en el mercado que finalmente le otorgó el Consejo Directivo de la Industria Azucarera luego de fracasada la proyectada ley, es algo que, por el momento, no podemos determinar a ciencia cierta. Lo que sí debemos señalar es que el acuerdo de ventas de azúcar previo al debate parlamentario se logró sostener, momento en el cual la CIASL se embarcó en su postrimera y frustrada zafra. El último convenio fue firmado en mayo de 1941, cuando ya el ingenio San Lorenzo llevaba un año paralizado, por lo que se prescindió de su aval para efectivizarlo. Dicho arreglo, sin embargo, nunca se cumplió integralmente a causa del impacto de la "plaga del carbón" en los cañaverales tucumanos durante las zafras 1941-1943, que llevó a incrementar la producción de los ingenios de otras zonas para abastecer la demanda interna y que habría beneficiado a la CIASL de mantenerse en operaciones.

Empero, las deficiencias en el eslabón agrícola de la cadena productiva, la falta de una infraestructura consolidada, las consecuencias de la plaga, las zafras discontinuas, el malogro de la cosecha de $1940 \mathrm{y}$ la posterior paralización del ingenio, representaron elementos determinantes para una empresa que ya evidenciaba claros signos de debilitamiento económico-financiero.

En la Tabla 3 presentamos los resultados de las distintas zafras llevadas adelante por la firma, además de una serie de indicadores sobre su estado económico-financiero. Como se puede observar, sólo en cinco campañas no consecutivas obtuvo beneficios, aunque en márgenes mínimos, incapaces de remontar los arrastres de pérdidas que se fueron acumulando en más de una década. Si a esto se agrega que en 1933 se invirtió el 67\% del capital suscripto en la construcción del ramal ferroviario (suma que no fue recuperada en su totalidad), la ruina que significó la plaga en los años 36-38 y el cierre parcial en 1939, además de los problemas para abastecerse de materia prima, resultan elementos acumulados más que significativos que contribuyen a la explicación de este fracaso empresarial. En efecto, a lo largo del ciclo histórico de la firma, pero sobre todo en los últimos años, los beneficios obtenidos en proporción a la inversión y los rindes de los recursos financieros fueron ínfimos cuando no negativos, lo que coadyuvó a pronunciar la merma tendencial de su solvencia. Evidentemente, la zafra de 1940, interpretada como un síntoma de recuperación, fue el canto del cisne de una empresa incapaz de realzar una producción mínima capaz de dejar márgenes de beneficios económicos aceptables. 
TABLA 3

Resultados, saldos y ratios de balance de CIASL (1929-1941)

\begin{tabular}{|c|c|c|c|c|c|c|}
\hline Ejercicios & Resultado & $\begin{array}{c}\text { Pérdidas } \\
\text { acumuladas } \\
(1929=100)\end{array}$ & $\begin{array}{c}\text { Rentabilidad } \\
\text { económica } \\
(\%)\end{array}$ & $\begin{array}{c}\text { Rentabilidad } \\
\text { financiera }(\%)\end{array}$ & $\begin{array}{c}\text { Situación de } \\
\text { solvencia (\%) }\end{array}$ & $\begin{array}{l}\text { Endeudamiento } \\
(\%)\end{array}$ \\
\hline 1929 & $(-) 111.202,11$ & 100 & $(-) 2,79$ & $(-) 0,0004$ & 2,36 & 29,75 \\
\hline 1930 & $32.030,99$ & 76 & 0,73 & 1,0140 & 2,59 & 27,89 \\
\hline $1931-32$ & $(-) 295.114,00$ & 287 & $(-) 6,19$ & $(-) 0,0009$ & 2,20 & 31,29 \\
\hline $1932-33$ & $2.865,88$ & 285 & 0,06 & 0,0882 & 1,92 & 34,25 \\
\hline $1933-34$ & $2.620,08$ & 283 & 0,04 & 0,0771 & 1,32 & 43,11 \\
\hline $1934-35$ & No informa & 279 & $\ldots$ & $\ldots$ & 1,09 & 44,93 \\
\hline $1935-36$ & $7.371,60$ & 273 & 0,14 & 0,2457 & 1,26 & 44,21 \\
\hline $1936-37$ & $1.140,10$ & 272 & 0,02 & 0,0389 & 1,18 & 45,85 \\
\hline $1937-38$ & $(-) 19.805,74$ & 290 & $(-) 0,41$ & $(-) 0,0001$ & 1,18 & 45,86 \\
\hline $1938-39$ & $(-) 115.121,63$ & 387 & $(-) 2,24$ & $(-) 0,0004$ & 1,16 & 46,25 \\
\hline $1939-40$ & $(-) 265.721,08$ & 617 & $(-) 4,76$ & $(-) 0,0010$ & 0,93 & 51,77 \\
\hline $1940-41$ & $(-) 74.958,86$ & 692 & $(-) 1,61$ & $(-) 0,0003$ & 1,02 & 49,38 \\
\hline
\end{tabular}

Fuente: Elaboración propia a partir de los Balances Generales de CIASL publicados en el Boletín Oficial de la Nación (años correspondientes)

Pérdidas acumuladas (Resultados más arrastres); Rentabilidad económica (Utilidades sobre Activo); Rentabilidad financiera (Utilidades sobre Capital propio); Situación de solvencia (Capital propio sobre Pasivo Exigible); Endeudamiento (Pasivo Exigible sobre Pasivo total). Los resultados fueron deflactados según el índice de precios al consumidor (año base 1935) (Ferreres, 2005)

La repercusión de este panorama en la Asamblea de Accionistas que realizó la firma apenas terminó el ejercicio 1940-41 (si observamos en la Tabla 1, a partir de 1935, aproximadamente, había cambiado la composición del directorio, manteniéndose Benito Raggio con capacidad de decisión), sumado a las pocas perspectivas de crecimiento en un futuro inmediato, derivaron en la autorización para vender la fábrica cuando se creyera oportuno, dada la situación delicada en que se encontraba la empresa. La acumulación de circunstancias desfavorables conspiró contra la continuidad del negocio y en noviembre de 1941 el directorio firmó el acta de venta. El total de las maquinarias e instalaciones fueron vendidas ese mismo año y adquiridas en alrededor de 2.000.000 de pesos por industriales azucareros del país y de Uruguay, suma que alcanzó para cubrir menos del 70\% de las deudas de la empresa, lo que grafica con elocuencia el estado de los pasivos.

En definitiva, fueron los socios los que propusieron la venta de las instalaciones para recuperar parte de lo invertido. Esto necesariamente debe sopesarse a la hora de analizar el derrotero de esta empresa. Los fracasos suelen estar asociados a una quiebra, aunque este término puede remitir también a un mal negocio, una pérdida considerable, una apuesta mal planificada o, simplemente, a una proyección que no resultó como se esperaba. En tal sentido, el éxito y la frustración, el triunfo y el colapso o la crisis representan componentes inherentes a un emprendimiento (Lluch, 2010, p. 376) y se los debe tomar como variables posibles de toda iniciativa empresarial. Lógicamente, las esperanzas que despertó un emprendimiento como la CIASL en la región del Valle Medio e Inferior del río Negro hacen difícil conferir que los reveses no siempre obedecen exclusivamente a causas ajenas, como creemos haber demostrado en esta primera aproximación a la temática. 


\section{BREVES REFLEXIONES FINALES Y FUTURA AGENDA DE TRABAJO}

A juicio del Instituto Agrario Argentino (1946, p. 132), las razones del fracaso de los principales intentos remolacheros, tanto en Cuyo como en Río Negro, nunca fueron suficientemente esclarecidas. Sin embargo, invitaba a buscarlas en los inconvenientes intrínsecos a la implantación de un nuevo cultivo; en las variedades de tubérculos no aptas desde el punto de vista económico y en el alto precio de la semilla; en la crisis sanitaria; en la falta de mecanización de etapas fundamentales de las labores, como así también en las dificultades de orden administrativo. Es factible que su Director, Alazraqui Alonso (férreo promotor de la industria remolachera en Argentina), omitiera aludir a la incidencia que pudo haber tenido el lobby de azucareros norteños. Sin embargo, las razones expresadas anteriormente son más que elocuentes para percibir las debilidades que acarreaba desde su origen dicha empresa. Además, a los vaivenes de la política azucarera nacional, se le sumó el incumplimiento de los prometidos apoyos institucionales para la provisión de la infraestructura necesaria en transportes y riego para el normal funcionamiento del ingenio conesino, lo que se tradujo en acciones precipitadas por parte de la empresa y compelidas por la fuerza de los hechos. La falta de apoyos políticos por fuera del territorio, debido a que Río Negro no poseía aún el status de provincia y por lo tanto no contaba con representantes en el Congreso Nacional, determinó la carencia de fuerza política para defender sus intereses.

A esto se debería agregar la falta de un estudio minucioso sobre las reales posibilidades y limitaciones para emplazar una novel agroindustria en áreas sin antecedentes de labranzas intensivas. Sin dudas, la quenopodiácea representa un cultivo con mayores rendimientos culturales y sacarinos que la caña de azúcar. Pero los tan mentados rindes sin parangón, en este caso, fueron más la excepción que la regla, pues en los distintos suelos variaban considerablemente, llegando a encontrarse zonas donde apenas se obtenían $15 \mathrm{t}$ por hectárea, algo totalmente antieconómico. Además, se debería justipreciar la pretendida rivalidad con los grandes ingenios cañeros del norte, puesto que la zafra de mayor éxito del San Lorenzo apenas representó el $1,3 \%$ del total de la producción azucarera nacional.

Si acaso se llegara a aceptar que la remolacha azucarera pudo haber representado un apremio a los tradicionales proveedores norteños, y si el San Lorenzo habría perecido por no encontrar un lugar en un mercado ya repartido entre los "grandes", correspondería exponer también los motivos por los que otras empresas azucareras sí tuvieron éxito al erigir nuevos ingenios cañeros en la misma época, no sólo en áreas con escaso desarrollo de la actividad, como en Santa Fe, sino en el mismo núcleo productor tucumano y salto-jujeño. Con todo, también debemos conceder que restan explicar las razones por las cuales ningún emprendimiento basado en el procesamiento de la remolacha logró perdurar en la Argentina hasta la actualidad, pese a nuevos intentos llevados a cabo posteriormente en diferentes provincias.

El apoyo científico brindado por las estaciones experimentales y los expertos contratados logró superar, en pocos años, la plaga de 1935. Pero no alcanzó para repuntar la producción lo suficiente como para revertir los resultados contrarios que arrojaron las últimas zafras de la CIASL, ni mucho menos atemperar el acumulado de una década con saldos negativos.

En síntesis, diversos factores incidieron en el fracaso de este intento de desarrollo de la industria remolachera rionegrina, desde cuestiones naturales, pasando por errores de planificación y proyectos no concluidos, hasta una evidente falta de medidas de estímulo, sin restar importancia al contexto institucional notoriamente desfavorable en que se desarrolló el ciclo de vida de esta firma.

Para un análisis micro, de mayor profundidad, resultaría imprescindible la consulta de las memorias internas o documentos que pudieran haber perdurado. Por lo pronto, desde hace algunos años, la concepción de la empresa como objeto de estudio que puede ser abordado desde diferentes perspectivas ha impulsado propuestas que colocan a la firma y su unidad productiva como epicentro de análisis a partir de las cuales es posible reconstruir el entramado de relaciones económicas y sociales al interior de estas, como también su proyección en el ámbito comunitario local y en el espacio productivo regional. Es aquí donde sería interesante 
centrar los esfuerzos futuros. Más que un estudio exclusivamente centrado en la Compañía, una pesquisa basada en estos presupuestos puede representar el camino que conduzca a mensurar de mejor modo el impacto que significó la instalación de este moderno ingenio en la región, como dijimos, sin un pasado industrial/manufacturero y con una agricultura incipiente ajustada a cultivos tradicionales.

En este sentido, sería auspicioso un estudio sobre el desenvolvimiento de esta empresa apuntalada por capitales regionales y extrarregionales, que a la vez aborde temáticas conexas como la reconversión del hinterland de Gral. Conesa impuesta por el nuevo modelo socioeconómico basado en el procesamiento de remolacha azucarera, los diferentes "derrames" o eslabonamientos que pudiera haber generado este enclave industrial tanto en el sector primario como el secundario, las experiencias de vida que perduraren en la memoria de los descendientes de trabajadores y empleados, y otras acciones propias de los estudios de rescate y preservación del patrimonio arquitectónico-industrial y cultural.

En definitiva, nos encontramos frente a un campo abierto cuya estrategia principal consiste en partir desde un objeto de estudio específico (en este caso el ingenio San Lorenzo), y desde allí pivotear en diferentes temáticas y engarzar procesos superpuestos. Esto no sólo significaría un avance en los estudios regionales sino que, al ubicar al accionar de la CIASL como centro de análisis y examinar sus efectos en su área de influencia, invita a repensar las complejidades que conllevó la implantación de la industria azucarera en espacios periféricos.

\section{APÉNDICE}

TABLA 1

Muestra de directores de CIASL con cargos en otras empresas

\begin{tabular}{|c|c|}
\hline Nombre & Empresa \\
\hline Antonini, Enrique & "Roma", Cía. Italo-Argentina de Seguros \\
\hline Camuyrano, Américo & "Vicente Pelufo y Cía. Ltda." (semillas, plantas y ganadería) \\
\hline $\begin{array}{l}\text { Etcheverrigaray, } \\
\text { Fabián }\end{array}$ & "El Cóndor", Cía. de Seguros/Banco de la Provincia de Buenos Aires \\
\hline Luchinetti, Arnaldo & $\begin{array}{r}\text { Banco de Italia y Río de la Plata/Cía. Argentina de Teléfonos/Corporación Sudamericana } \\
\text { de Teléfonos y Telégrafos/"La Inmobliaria", Cía. de Seguros/Celulosa Argentina/Cía. } \\
\text { Entrerriana de Teléfonos }\end{array}$ \\
\hline Magliones, Francisco & Banco de "El Hogar Argentino"/"El Sol Argentino", Cía. de Seguros \\
\hline Minuto, José & Mercado de Abasto Proveedor \\
\hline Olaciregui, Ramón & $\begin{array}{r}\text { "Santa Blanca" (Pasteurizadora)/Fábrica Argentina de Máquinas agrícolas/"San } \\
\text { Martín", Cía. de Seguros/S. A. "Lanusse y Olaciregui Ltda.", miembro de la Sociedad } \\
\text { Rural de Bahía Blanca }\end{array}$ \\
\hline Pegasano, Juan & "Roma", Cía. Italo-Argentina de Seguros \\
\hline Raggio, Benito L. & $\begin{array}{r}\text { nera del Norte; "La Buenos Aires", Cía. } \\
\text { de Seguros }\end{array}$ \\
\hline Raggio, Lorenzo & Casa Mayorista \\
\hline Repetto, Luis Andrés & Mercado del Abasto Proveedor \\
\hline Terrabusi, Humberto & ntina de Seguros, "Terrabusi Hnos" \\
\hline
\end{tabular}

Fuente: Elaboración propia a partir de Guía de Sociedades Anónimas (1926-1942) 
FIGURA 1

Mapa de la provincia de Río Negro (ex Territorio Nacional)

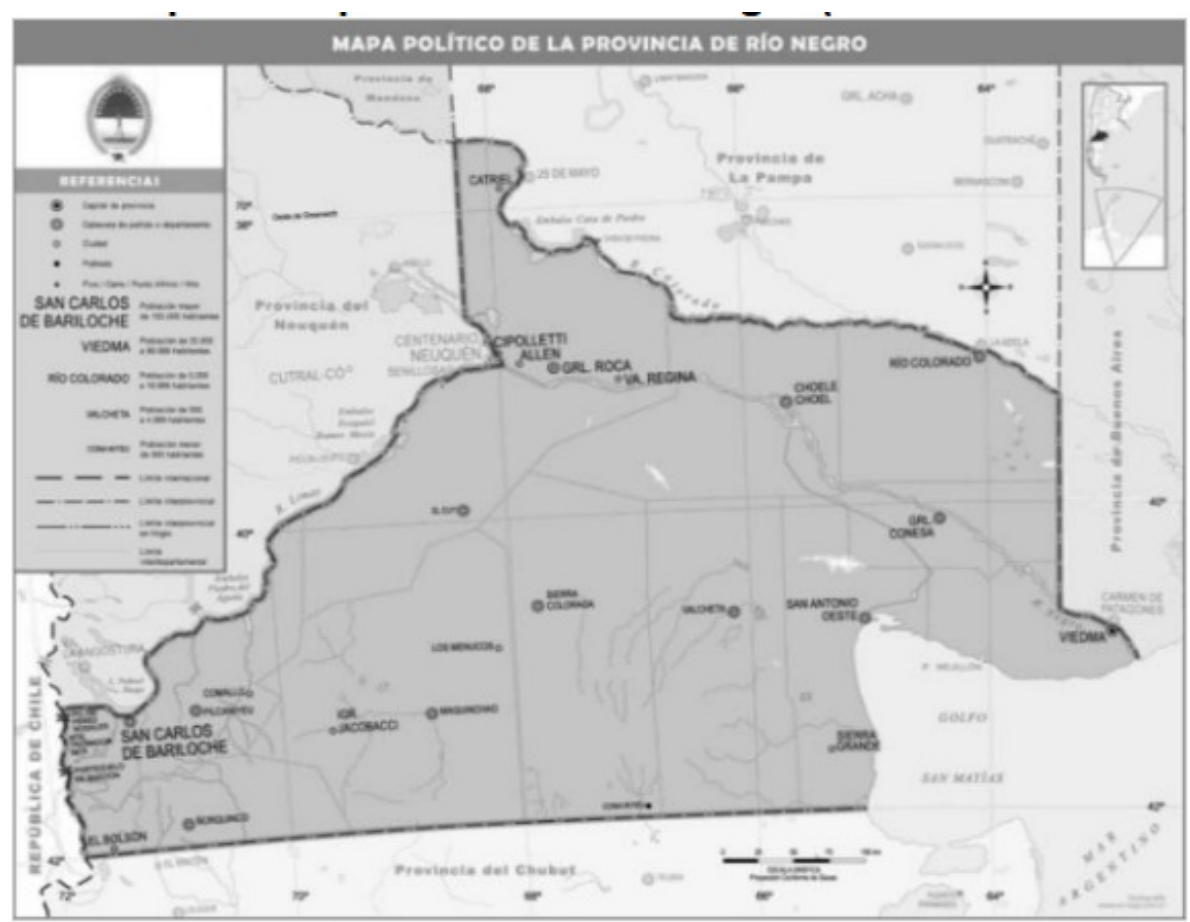

Fuente: http://mapoteca.educ.ar/.files/index.html.1.21.html

FIGURA 2

Plano del Valle Medio e Inferior del Río Negro con la ubicación del ingenio San Lorenzo

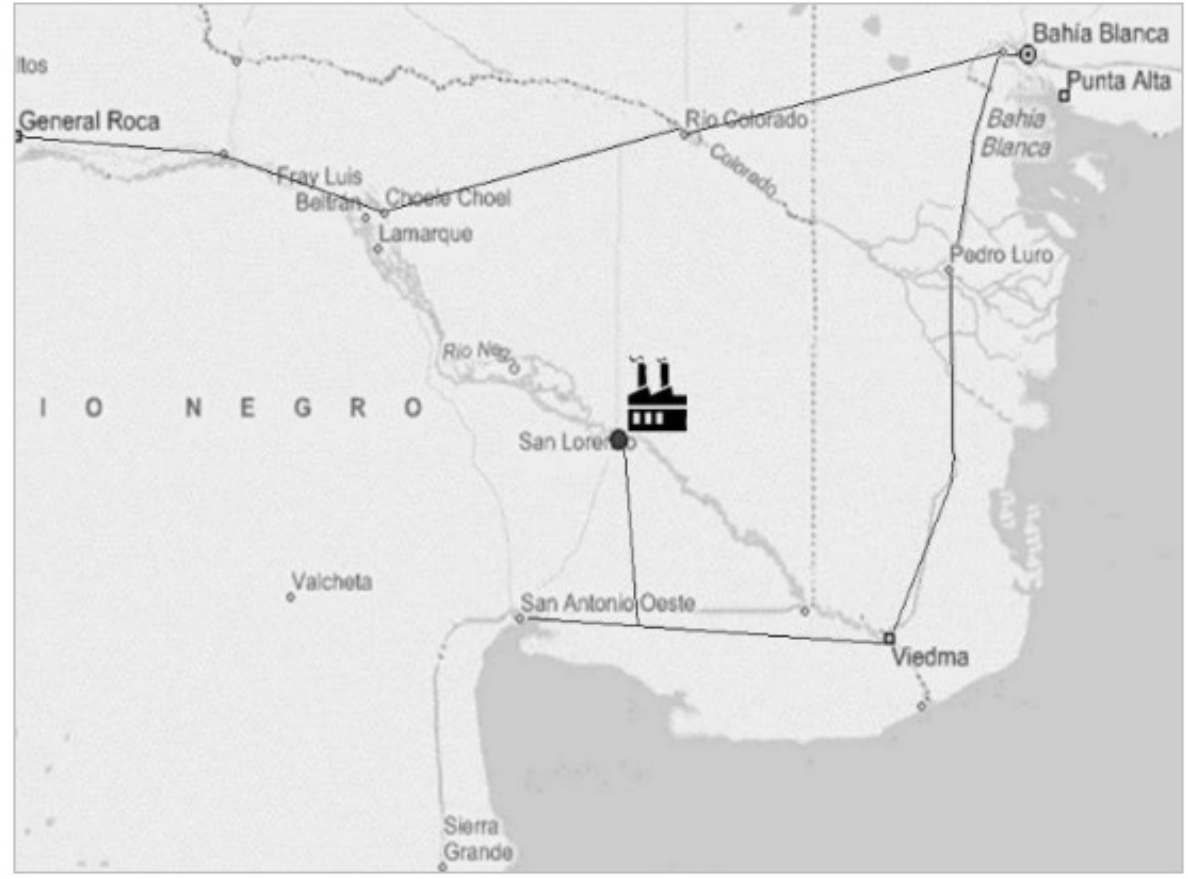

Fuente: http://mapoteca.educ.ar/.files/index.html.1.21.html 


\section{BiBLIOGRAFÍA Y FUENTES CITADAS}

Alazraqui Alonso, J. (1964). Remolacha azucarera. Antecedentes para la República Argentina. Buenos Aires.

Barcia Trelles, J. (1922). Agricultura de regadío en los Valles Superior del Río Negro e Inferior del Neuquén y Limay. F.C. Sud (Folleto n ${ }^{\circ}$ 9): Buenos Aires.

Bandieri, S. y Blanco, G. (1998). Pequeña explotación, cambio productivo y capital británico en el Alto Valle del río Negro. Quinto Sol, 2, 25-63.

Bandieri, S., Blanco, G. y Bessera, E. (2017). El proyecto de desarrollo patagónico de Ezequiel Ramos Mexía y el rol de la 'Comisión de Estudios Hidrológicos' dirigida por Bailey Willis, Prefacio Histórico. En G. de Jong, E. Bessera y M. Mare (coords), Estrategias y Proyectos, Comisión de Estudios Hidrológicos Bailey Willis 1915-1938, Tomo II. Neuquén: EDUCO -Editorial UNCo.-/Convenio APN-CONICET-UNCo.-.

Bennet, C. y Munck, C. (1946). Yellow Wilt of sugar beet in Argentina. Journal of Agriculture Research, 73(2).

Bravo, M. (2008). Campesinos, azúcar y política: cañeros, acción corporativa y vida politica en Tucumán (1895-1930). Rosario: Prohistoria Ediciones.

Bravo, M. y Gutiérrez, F. (2014). La política azucarera argentina: de la concertación sectorial al tutelaje estatal (1928-1949).H-industri@,8(14),153-185.

Campi, D., Teruel, A. y Moyano, D. (2017). La región del azúcar. Tucumán, Salta y Jujuy (1895-1940). En S. Bandieri y S. Fernández (coords.), La historia nacional en perspectiva regional. Nuevas miradas para viejos problemas (vol. 1, pp. 387-436). Buenos Aires: Teseo.

Centro Azucarero Argentino (1935). La Industria Azucarera. Buenos Aires: Ferrari Hnos.

De Groof, B., Geli, P., Stols, E. y Van Beeck, G. (eds.) (1998). En los deltas de la memoria. Bélica y Argentina en los siglos XIX y XX. Leuven (Bélgica): Leuven University Press.

Deerr, N. (1950). The History of Sugar (vol. 2). London: Chapman and May Ltd.

Estación Experimental Agrícola de Tucumán (1917-1926). Revista Industrial y Agrícola de Tucumán. Tucumán.

Ferrarazzo, E. (1938). La Patagonia y la industria azucarera argentina. Sud-Oeste, 13(155), 32-39.

Ferreres, O. (dir) (2005). Dos siglos de economia argentina, 1810-2004. Historia argentina en cifras. Buenos Aires: El Ateneo/Fundación Norte y Sur.

Girbal-Blacha, N. (2017). La acción legislativa invisible. Propuestas frustradas para la economía azucarera argentina (1920-1960). Revista de Ciencias Sociales, Segunda época, 32, 131-155.

Gómez, R. (1949). Fundamentos de la política económica de la industria azucarera argentina. Universidad de Buenos Aires, Facultad de Ciencias Económicas: Buenos Aires.

Guías de Sociedades Anónimas (1927-1942). Comercio e Industria: Buenos Aires.

Instituto Agrario Argentino (1946). La remolacha azucarera. Cultivo e industrialización en la República Argentina. Buenos Aires: Editorial La Platense.

La Industria Azucarera. Órgano del Centro Azucarero Argentino (1920-1941), Buenos Aires

Laría, A. (22 de julio de 1979). Hace 50 años en General Conesa, Río Negro inició la fabricación de azúcar de remolacha. Rio Negro.

Lluch, A. (2010). El fracaso en el mundo empresario argentino: Una aproximación desde el análisis de os 'quebrantos comerciales' (1900-1930). Anuario IHES, 25, 375-393.

Luna, I. (2007). Vivencias de mi gente II. Ingenio Azucarero de remolacha. Historia Oral, Gral. Conesa, Río Negro, Patagonia argentina. Carmen de Patagones: Imprenta Minigraf.

Martocci, F. (2011). Enseñar a cultivar en el Territorio pampeano. Escuelas, agronomias y estaciones experimentales (1900-1953). Anguil: INTA-IESH.

Mc Callum, D. (1959). La remolacha azucarera: politica económica a seguir para su reimplantación en la Argentina. Buenos Aires: Universidad de Buenos Aires, Facultad de Ciencias Económicas.

Menni, E. (28 de octubre de 1981).Aspectos históricos del cultivo de la remolacha azucarera. Río Negro. 
Moyano, D. (2015). Construyendo el mercado para el azúcar argentino. Un análisis sobre los intermediadores y las canales de comercialización (1885-1905). En Lluch, Andrea (ed.), Las manos visibles del mercado: Intermediarios $y$ consumidores en la Argentina (Siglos XIX y XX) (pp. 49-79). Rosario: Editorial Prohistoria/EDULaPam.

Muñoz, J. (1952). La industria de la remolacha azucarera. Buenos Aires: Universidad de Buenos Aires, Facultad de Ciencias Económicas.

Oreja, P. (1982). Desde la cúpula (memorias de un diputado patagónico). Gral. Roca: Ed. Río Negro.

Oreja, P. F. (1 de enero de 1962). El alto costo político de los planes de desarrollo nacional. Río Negro.

Pesatti, P. (8 de septiembre de 2007). El Ingenio de Conesa. Río Negro.

República Argentina (1938). Censo Industrial de 1935. Buenos Aires: Talleres de la S.A. Casa Jacobo Peuser.

República Argentina (1939a). Censo Nacional Agropecuario. Año 1937. Buenos Aires: Guillermo Kraft Ltda.

República Argentina (1939b). Estadística Industrial de la República Argentina correspondiente al año 1937. Buenos Aires.

República Argentina (1940). Estadística Industrial de la República Argentina correspondiente al año 1938. Buenos Aires.

Rey, H. y Vidal, L. (coord.) (1974). Historia de Rio Negro. Viedma: Ministerio de Asuntos Sociales, Consejo Provincial de Educación.

Schleh, E. (1939). Compilación Legal sobre el Azúcar (T. 6, pp. 69-89). Legislación de Varias Provincias, Buenos Aires: Editado por el Centro Azucarero Argentino.

Schleh, E. (1944). Cincuentenario del Centro Azucarero Argentino. Desarrollo de la industria en medio siglo. Buenos Aires: Centro Azucarero Argentino.

Sociedad Rural Argentina. (1954). Cultivo de la remolacha azucarera. Anales de la Sociedad Rural Argentina. Revista Pastoril y Agricola, 88(4).

Vapñarsky, C. (1983). Pueblos del Norte de la Patagonia 1779-1957. Gral. Roca: Editorial de la Patagonia.

\section{Notas}

1. Los avances tecnológicos iniciados en la industria del azúcar de remolacha a mediados del siglo XIX y los estímulos que le brindaron los diferentes Estados - protección aduanera de sus mercados y subsidios a la producción y a la exportación-, acentuaron la competencia con las tradicionales regiones cañicultoras, llegando a superarlas en términos de producción a finales de esa centuria. A causa de la Gran Guerra, la tendencia se revirtió en favor de los centros azucareros tropicales. Pero una vez reconstruido el aparato productivo europeo en una economía de paz, la creciente competencia entre ambas agroindustrias volvió a afectar el equilibrio del mercado mundial de azúcar (Deerr, 1950, p. XXIX).

2. Un análisis sobre la experimentación científica y la extensión agrícola por parte de agrónomos contratados por las empresas ferroviarias al sur de la pampa húmeda, en Martocci (2011). Con respecto al Alto Valle del río Negro, véase (Bandieri y Blanco, 1998).

3. Recuérdese que, una vez apropiadas las tierras que ocupaban las sociedades indígenas en el nordeste y sur del actual territorio argentino, se dictó la ley 1.532 en 1884 por la cual se crearon los Territorios Nacionales -entre ellos el de Río Negro-, se establecieron sus límites, forma de gobierno y administración. Hasta mediados de la década de 1950, en que se convirtieron en provincias, fueron divisiones administrativas carentes de autonomía y dependientes del gobierno central, el cual elegía directamente a sus autoridades y administraba sus rentas. Tampoco contaban con representantes en el Congreso de la Nación y sus habitantes no votaban en las elecciones nacionales.

4. De hecho, son esos los términos en que se planteó la discusión del proyecto de ley de regulación azucarera en las sesiones de la Cámara de Senadores de enero de 1939, donde se atribuyó a Padilla haber realizado acuerdos previos en ese sentido con grandes grupos industriales de Salta y Jujuy, hecho que el propio Ministro reconoció ( La Industria Azucarera, 1939, n. $\left.{ }^{\circ} 534: 23\right)$.

5. Archivo Histórico de la Provincia de Río Negro (en adelante AHPRN), El Atlántico (1939).

6. El presente apartado se respaldó, en gran medida, en las informaciones y opiniones vertidas en AHPRN, El Atlántico (1939), Laría (1979), Menni (1981), Oreja (1982), Luna (2007), Pesatti (2007).

7. El Ingenio San Lorenzo estuvo ubicado sobre la margen derecha del río Negro, $200 \mathrm{~km}$ aguas arriba de su desembocadura en el mar. En el lugar aún quedan restos de las antiguas edificaciones. Un documental que rescata la memoria local y que 
a la vez basa su línea argumental en esta versión de los acontecimientos, en Ontiveros, R; Menna, F, Parodi, C; Manca, B. (2008) "El Ingenio San Lorenzo". Disponible en https://elingeniosanlorenzo.blogspot.com.ar/

8. AHPRN, La Nueva Era, 1/7/1929; Río Negro, 13/6/1929, 27/6/1929 y 11/7/1929.

9. Estos datos los proporcionó el hijo de Benito Raggio, Lorenzo, en entrevista publicada en el principal medio de prensa regional. AHPRN, Rio Negro, 8/9/1966.

10. Se calculaba en 450 t diarias de remolacha el poder de procesamiento de la fábrica que, con un rendimiento industrial estimado de 16,5\% de sacarosa durante una zafra ininterrumpida de 120 días, permitiría alcanzar las 9.000 t de azúcar blanca por temporada. AHPRN, carta "Reservada" del gobernador Pagano con fecha el 13/9/1938; La Razón, 22/9/1936; Ferrarazzo (1938, p. 37).

11. Véase La Razón, "Para dar vida al Norte no es necesario matar al Sur", 8/10/1938 y 4/7/1940. Este medio de tirada nacional se ocupó exhaustivamente del tema y mostró su preocupación por el futuro de las plantaciones de remolacha en la localidad de Pedro Luro, al sur de la provincia de Buenos Aires.

12. AHPRN, Rio Negro, 20/9/1949.

13. En el año 1958 los diputados por la nueva provincia de Río Negro, Julio Rajneri y Alberto Rionegro, propusieron la creación de la sociedad mixta EMAR -Empresa Mixta de Azúcar Rionegrina-, con un capital de 150 millones de pesos, de los cuales 20 millones corresponderían a la provincia y el resto sería suscripto por agricultores, comerciantes e industriales de la región. Dicho proyecto no prosperó, pero es interesante señalar que no sólo se remarcaba los rendimientos superiores de la remolacha azucarera en relación a la caña de azúcar, sino que se volvía a hacer alusión "a la permanente decisión de los grupos azucareros del Norte de quebrar de raíz la incipiente industria rionegrina” (ADRN, Rio Negro, 13/8/1958). Cabe recordar que Julio Rajneri era miembro de una de las familias más destacadas de la provincia, con amplia trayectoria política y económica, además de ser los dueños del diario Río Negro, el más importante a nivel regional, creado en 1912.

14. Benito Raggio formaba parte de la importante firma comercial "Raggio Hermanos", cuya sede estaba ubicada en el tradicional barrio porteño de Monserrat, en la ciudad de Buenos Aires. Era integrante de una familia con amplia trayectoria en el rubro comercial e inmobiliario y en los negocios bursátiles. Uno de sus miembros, Rómulo, fue fundador y primer presidente del Mercado de Títulos y Valores - hoy Mercado de Valores- de la Bolsa de Comercio de Buenos Aires.

15. Los Raggio, además del comercio mayorista, operaban un molino de maíz y una fábrica de fideos. Otro de los integrantes del directorio primigenio, Humberto Terrabusi, pertenecía a la conocida empresa fabricante de galletitas Terrabusi Hnos. En todos los casos, representaban ramas industriales menores en comparación con las escalas de un emprendimiento agroindustrial como lo representa un ingenio azucarero. Además, se puede mencionar las actividades de Juan Pegasano, el primer presidente de la CIASL, con funciones en otras empresas como la Roma, Cía. Italo-Argentina de Seguros o Pegasano y Cía., dedicada a la compra-venta de inmuebles rurales; y también de Ramón Olaciregui, uno de los directivos más destacados por su trayectoria como empresario y por haber integrado el directorio en casi todo el ciclo de la empresa. Comerciante y ganadero de Bahía Blanca, fue miembro fundador de la Sociedad Rural bahiense y del Centro comercial de Bahía Blanca (este último agrupaba tanto a comerciantes mayoristas como minoristas, incluidos aquellos que se dedicaban a la venta de granos, lanas y ganado).

16. Desde el punto de vista agrícola, las zonas ecológicas de Buenos Aires con mayor aptitud para el desarrollo de la remolacha azucarera comprendían los partidos de Balcarce, Gral. Pueyrredón, Gral. Alvarado, Lobería y Necochea (Sociedad Rural Argentina, 1954, p. 158). También se llevaron a cabo cultivos, tanto extensivos como experimentales, en los partidos de Tandil, San Cayetano, Tres Arroyos, Adolfo González Chaves, Benito Juárez, Villarino y Patagones (Alazraqui Alonso, 1964).

17. La ley provincial $N^{\circ} 3.264$ de 1910 concedió a Riccheri un privilegio por 15 años para instalar fábricas de remolacha en Buenos Aires. Su intención era tentar a inversores de Bélgica -país donde había desarrollado sus estudios e influenciaspara la construcción de ingenios en el interior de la provincia, aunque esta tentativa fracasó por falta de confianza en el futuro del rubro. Mediante otorgamientos posteriores, se extendió la concesión hasta principios de los años 1940 para llevar a cabo un emprendimiento que nunca vio la luz. Véase De Groof (1998, p. 28); Schleh (1939, pp. 95-98).

18. "la remolacha azucarera puede estar llamada a producir una profunda y benéfica revolución en la economía rural del Río Negro, ya que pensamos que esta preciosa raíz azucarera ha de prosperar en el valle y producir la baja del precio del azúcar, dejando un notable margen de ganancias para el agricultor y para el industrial (...) La riqueza sacarina es asombrosa, pues en Europa se considera buena la de 14 a 15 por ciento; excelente la de 16 por 100 y excepcional la de 17 por ciento; es decir, que el porcentaje minimo de nuestras raíces representa el excepcional europeo" [cursivas en el original] (Barcia Trelles, 1923, pp. 20-22). Los ensayos se realizaron entre 1920 y 1925.

19. Un completo cuadro con los resultados de las primeras experiencias con cultivos de remolacha azucarera en el centrosur de la Argentina, puede consultarse en Alazraqui Alonso (1964, p. 43). Una opinión favorable a la expansión de esta agroindustria patagónica la otorgó Enrique Ferrarazzo, conocedor de la problemática azucarera al haber actuado como árbitro en el conflicto fabril cañero de la provincia de Tucumán (Ferrarazzo, 1938, pp. 33-39). 
20. La firma comercial de Raggio no formó parte del grupo de las mayores casas comercializadoras que controlaban la oferta en el mercado interno. Sin embargo, operó con una sólida presencia en la zona central del país y en la costa atlántica. Para una visión general sobre las cadenas de comercialización del azúcar a fines del siglo XIX e inicios del siglo XX, véase Moyano (2015).

21. Los primeros pasos de este proyecto parecieron lograrse, por lo menos en parte, hasta el ataque de la plaga a los cultivos. En 1935, el Centro Azucarero señalaba: "En cuanto a la fábrica de Río Negro, ha aumentado gradualmente su producción hasta pasar las 3.000 toneladas de azúcar al año. Surte del producto a la región y en parte lo remite a las poblaciones hasta Bahía Blanca" (Centro Azucarero Nacional, 1935, p. 89).

22. Esto atendiendo a la negativa de la empresa Ferrocarriles del Estado, que había retomado la construcción del ramal que uniría a San Antonio Oeste con San Carlos de Bariloche -fijado por la Ley de Fomento de los Territorios Nacionales de 1908 (Bandieri, Blanco y Bessera, 2017, p. 24) - y que consideraba que los capitales británicos no debían intervenir en su zona de influencia (La Industria Azucarera, 1939, n. ${ }^{\circ}$ 543: 20).

23. La definitiva aprobación del proyecto para dotar de riego a una zona de 20.000 ha en el Valle Medio -Distrito de Riego Conesa- se postergó hasta 1935. La habilitación de la red de canales y desagües se efectivizó recién entre los años 1951 y 1960 (Vapñarsky, 1983, p. 308).

24. Según Lorenzo Raggio, recién en 1955 el Estado devolvió lo que adeudaba de esta inversión, sin reconocimiento alguno de intereses ni devaluaciones monetarias (Luna, 2007, p. 28).

25. Esta enfermedad fue descripta como "Chlorogenies patagoniensis" por quienes la identificaron en EE.UU. y estudiaron la posibilidad de producir una semilla resistente (Bennet y Munck, 1946).

26. "En 1937 ó 1938 se sembró allí remolacha azucarera para venderla al ingenio San Lorenzo, que la compraba según peso en el ingenio. De esa manera los pesos o los rindes de la remolacha azucarera eran inferiores a los que podían haber tenido en los puntos de embarque. Tal circunstancia determinó que en la zona de Lobería los productores renunciaran a continuar cultivando remolacha azucarera para entregar al ingenio San Lorenzo. Fue una explotación por un año o dos de los productores de remolacha azucarera de la zona (...)" (Cámara de Diputados, 2/8/1961, p. 2.055).

27. Colonias San Lorenzo (221 ha), La Luisa (243), San Juan (560); en Valcheta 100 ha y cerca de Viedma, en Laguna Juncal, 60 ha, totalizando 1.184 ha (Anuario Frutícola-Industrial, 1937)

28. En Río Negro se mantuvieron ocho explotaciones en General Conesa con 772 ha bajo cultivo y con un rendimiento cultural de 11,5 t por ha, mientras que en Valcheta continuaron tres explotaciones con un total de 8 ha y con un rendimiento de casi $19 \mathrm{t}$ por ha. Si acaso la segunda área se vio menos perjudicada por la plaga, ciertamente eran superficies ínfimas, incapaces de aprovisionar al ingenio. (República Argentina, 1939a, p. 193).

29. En 1935, de las 33.340 t procesadas, el $96 \%$ correspondió a materia prima de terceros. En 1937, el total descendió a 8.633 t con una participación del $87 \%$ de remolacha comprada. Para la zafra de 1938, tan solo se procesaron 3.332 t de raíces, de las cuales el 76\% fue adquirida a cultivadores de la zona (República Argentina, 1936, 1938, 1939b).

30. Nada más cercano a la "plaga del mosaico" (mosaic virus) que arrasó los cañaverales tucumanos entre 1915 y 1917; o a la plaga del "carbón" (ustilago scitaminea) que afectó a las plantaciones de caña norteñas en las zafras 1941-1943. En ambos casos, fue posible superar las contingencias gracias al asesoramiento inmediato y el replante con cañas desarrolladas en la Estación Experimental Agrícola de Tucumán, una institución dedicada al desarrollo científico-tecnológico de la actividad y solventada por la misma agroindustria.

31. Estas y otras interpretaciones recargadas pueden encontrarse en AHPRN, El Atlántico (1939) bajo el título "Tierra Castigada".

32. Como señalara años después Pablo F. Oreja, diputado por la provincia de Río Negro: "Lo que mató a ambos ingenios [de Media Agua y de San Lorenzo] fue la decisión política de los ‘barones del azúcar’ de Salta y Jujuy, poderosamente representados en el Congreso de la Nación, mientras Río Negro, por ese tiempo, era un territorio perdido en la Patagonia, sin voz ni voto en las cámaras. La ley del año 1938 le fijó una cuota de 3.500 toneladas por año y un incremento anual de 60 toneladas (...) esto y decir, llanamente, que el ingenio debía cerrarse, era la misma cosa” (Oreja, 1982, p.146).

33. Un completo análisis sobre la temática en Bravo (2008, pp. 265-321).

34. El Consejo formaba parte de una entidad principal denominada Asamblea General de Industriales, y estaba subdividido en Comité de Ventas, Comité de custodia de stock, Comité de presupuesto, Comité de propaganda, Dirección General de control y otras reparticiones menores.

35. La distribución de las cuotas se basó en un estimado de consumo total prorrateado de la siguiente manera: 71\% Tucumán, 24\% Salta-Jujuy y $4 \%$ el resto del país (Santa Fe, Corrientes, Chaco y Río Negro). Si el consumo aumentaba, el faltante sería cubierto en la siguiente proporción: $48 \%$, 47\% y 5\% respectivamente. Los cupos fueron asignados de acuerdo a la producción de la zafra de 1938. Sin embargo, si un ingenio hubiera elaborado menor cantidad que el año inmediatamente anterior, se realizaría un promedio de las tres últimas campañas (1936-1938) a fin de compensarlo. Pese a este reajuste, el ingenio San Lorenzo seguía corriendo en desventaja, pues en 1936 ya había recibido el impacto de la plaga, reduciendo en un $50 \%$ su producción. Por ese motivo, la CIASL buscaba que se incluyera en el promedio la zafra de 1935 para 
atemperar la reducción, algo bastante improbable en tanto sería reclamado por todos los ingenios con la consiguiente modificación íntegra de los cálculos.

36. AHPRN, Carta de la CIASL al Gobernador del Territorio Nacional de Río Negro, Adalberto Pagano, y al presidente de la Comisión de Agricultura del Senado de la Nación, Laureano Landaburu, fechada el 9/9/1938. Carta "Reservada" del gobernador rionegrino Adalberto Pagano al Mtro. del Interior Diógenes Taboada, fechada en Viedma, el 13/9/1938, sobre "Posición del Territorio de Río Negro frente al proyecto de regularización de la industria azucarera".

37. Los debates y las referencias a la situación de los ingenios del Litoral y Río Negro pueden consultarse en Schleh (1939, pp. 107-329). También en La Industria Azucarera (1938 y 1939). 